\title{
INDIVIDUAL-LEVEL CONTACT LIMITS PHONOLOGICAL COMPLEXITY: EVIDENCE FROM BUNCHED AND RETROFLEX / $/ \mathbf{s}$
}

\author{
JEFF MiELKe \\ North Carolina State \\ University \\ ADAM BAKER \\ University of North Dakota
}

Diana ArChangeli

University of Arizona and University of Hong Kong

We compare the complexity of idiosyncratic sound patterns involving American English / $/$ / with the relative simplicity of clear/dark /1/-allophony patterns found in English and other languages. For $/ \mathrm{x} /$, we report an ultrasound-based articulatory study of twenty-seven speakers of American English. Two speakers use only retroflex $/ \mathbf{x} /$, sixteen use only bunched $/ \mathbf{x} /$, and nine use both $/ \mathrm{x} /$ types, with idiosyncratic allophonic distributions. These allophony patterns are covert, because the difference between bunched and retroflex $/ \mathrm{I} /$ is not readily perceived by listeners. We compare this typology of $/ \mathrm{A} /$-allophony patterns to clear/dark $/ 1 /$-allophony patterns in seventeen languages. On the basis of the observed patterns, we show that individual-level $/ \mathrm{x} /$ allophony and language-level /1/ allophony exhibit similar phonetic grounding, but that $/ \mathrm{x} /$-allophony patterns are considerably more complex. The low complexity of language-level /1/-allophony patterns, which are more readily perceived by listeners, is argued to be the result of individual-level contact in the development of sound patterns. More generally, we argue that familiar phonological patterns (which are relatively simple and homogeneous within communities) may arise from individuallevel articulatory patterns, which may be complex and speaker-specific, by a process of koineization. We conclude that two classic properties of phonological rules, phonetic naturalness and simplicity, arise from different sources.*

Keywords: rhotic, lateral, allophony, contact, ultrasound, complexity

1. InTRODUCTION. The recent history of linguistics has seen phonology become increasingly a laboratory science. While many of the fundamental questions remain the same (e.g. What is a possible language? Why are some phonological patterns more common than others? What is the mental representation of these patterns?), the range of tools available for addressing these questions has increased substantially. The development of the sound spectrograph in the mid-twentieth century gave rise to an explosion of phonetically informed phonological work (Jakobson et al. 1952, Halle 1959, Chomsky \& Halle 1968, Stevens 1972, et seq.), and phonology has continued to embrace technological innovations. Laboratory phonology has been brought into the mainstream by the wider availability of techniques for investigating the phonetic aspects of sound patterns. The most significant developments in this area are probably the availability of modern personal computers, digital recording, and open-source software, especially Praat (Boersma \& Weenink 2007), and consequently the ability of virtually any linguist to study sound patterns acoustically. While the study of speech articulation also has a long history (Ladefoged 1957, Fromkin \& Ladefoged 1966, inter alia), developments in ultrasound imaging (e.g. MacKay 1977, Stone et al. 1983, Stone 2005) have made it possible for more linguists to study the articulation of sound patterns. Articulation has the potential to provide an additional 'window' into the nature of phonology, by revealing details about the organization of sound patterns that are simply unavailable in the acoustic output. Ultrasound imaging, because it is safe, often portable, and relatively af-

* This work was supported by the College of Social and Behavioral Sciences at the University of Arizona, James S. McDonnell Foundation grant \#220020045 BBMB to Diana Archangeli, and SSHRC grant \#4102010-0552 to Jeff Mielke. Earlier stages were presented at the 2006 LSA meeting and LabPhon 10 and appeared in Mielke et al. 2010 and Archangeli et al. 2011. This project has benefited from Christopher Carignan, Robin Dodsworth, and Lyra Magloughlin, and this article has benefited greatly from comments by an associate editor and two anonymous referees. 
fordable, enables linguists to study the articulation of more speakers than were previously practical to study, leading to articulatory studies of linguistic variation.

A particularly good candidate for articulatory variation studies is North American English $/ \mathrm{d} /$, which can be produced by means of completely different tongue postures, including bunched and retroflex (Delattre \& Freeman 1968, et seq.). These different articulations are well known, as is the observation that the different configurations do not make a perceptible difference to the listener. That is, in contrast to many other linguistic variables, whether a person is bunching or retroflexing is not apparent just from listening.

We show, on the basis of ultrasound video of the tongues of twenty-seven native speakers of American English, that speakers who use more than one distinct $/ \mathrm{I} /$ tongue posture typically use each allophone consistently in different contexts, do so in the interest of articulatory ease, and differ quite a bit from one another in their allophony patterns. Compared to superficially similar sound patterns such as clear/dark $/ 1 /$ allophony, $/ \mathbf{x} /$ allophony appears to be peculiar in that it shows complex speaker-specific allophony patterns, with different conditioning segments for different syllable positions and different segmental contexts. We argue that the relative simplicity of /1/ allophony and other familiar sound patterns is due to a simplification process akin to koineization, and that $/ \mathrm{I} /$ allophony is complex and speaker-specific because the perceptual indistinctness of the variants prevents idiosyncratic patterns from reaching a stage of conventionalization.

Many aspects of English / $/$ / production are quite well documented. In $\S 2$, we review the literature on American English / $\mathbf{x} /$ articulation, which addresses the range of tongue postures used, phonetic conditions on their use, and mechanisms by which multiple tongue postures can achieve essentially the same acoustic output. Comparatively less is known about the nature of individual allophony patterns, and how phonetically motivated constraints on $/ \mathbf{x} /$ tongue posture interact with each other. We address $/ \mathbf{x} /$ allophony with the first articulatory study of American English / $\mathbf{x} /$ to involve a large number of speakers producing multiple repetitions of words with $/ \mathrm{x} /$ in a wide range of segmental contexts, large enough to assemble a typology of individual $/ \mathrm{x} /$-allophony patterns $(\S 3)$. While a major goal of this work is to document $/ \mathbf{x} /$ allophony in more detail, another goal is to investigate how the patterns are manifested in individuals, that is, the phonological nature of $/ \mathrm{x} /$ allophony.

In $\S 4$ we report a survey of documented cases of /1/ allophony and contrast them with English / $/ \mathbf{A}$ allophony. Allophonic variation between bunched and retroflex $/ \mathrm{x} /$ is similar in many ways to allophonic variation between clear and dark $/ 1 /$. Both sets of phenomena show similar ranges of phonetically motivated segmental and prosodic conditioning. In $\S 5$, we discuss the differences and their implications for phonology. Chief among the differences is that contact-induced convergence and simplification cannot occur in cases of covert allophony, and we argue that this results in the complex, phonetically motivated idiosyncratic patterns we observe.

2. Tongue postures for american english / $/$ /. Delattre and Freeman (1968) described eight tongue postures for $/ \mathbf{x} /$ based on $\mathrm{x}$-ray tracings, shown in Figure 1 . The tongue postures can be grouped into a few categories. Types 1 and 2 are the tongue postures used for postvocalic $/ \mathbf{x} /$ in r-less dialects (e.g. varieties spoken in Southern Britain and Eastern New England). ${ }^{1}$ Types 3 and 4 involve a dorsal constriction, and types 5

\footnotetext{
${ }^{1}$ Throughout this article we use / $\mathrm{x} /$ as the default transcription for the approximant $\mathrm{R}$ of American English. We choose ' $\mathrm{I}$ ' because it is a simpler symbol than ' $\mathrm{t}$ ', and not to suggest an implicit analysis of $/ \mathrm{I} /$ allophony with $[x]$ as the default allophone. Where they need to be distinguished in transcriptions, we use $[x]$ and $[x]$, and
} 


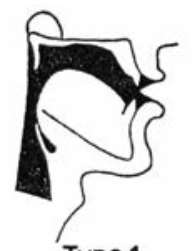

Type 1

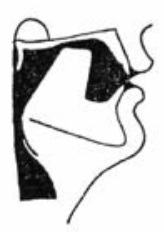

Type 5

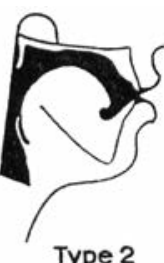

Type 2

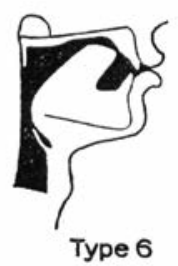

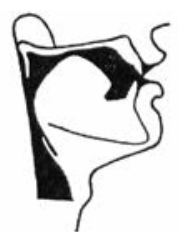

Type 3

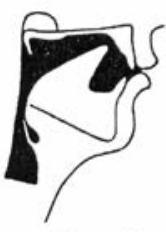

Type 7

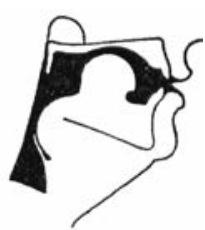

Type 4

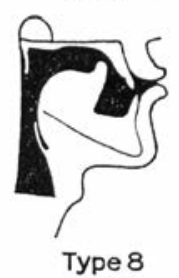

FIGURE 1. The Delattre and Freeman/s/taxonomy (Delattre \& Freeman 1968:41), printed with the permission of Walter de Gruyter GmbH. Copyright 2009.

and 6 involve tongue-blade raising. Types 7 and 8 are the retroflex tongue shapes. Delattre and Freeman, as well as Tiede and colleagues (2004), report finding types 2-7 in American English, but not in British English. Delattre and Freeman found types 1 and 8 almost exclusively in British English. ${ }^{2}$ Most ways of producing $/ \mathbf{x} /$ involve constrictions in the pharynx and the palatal vault, and a lip constriction often is present as well, especially in onset position. The r-less types 1 and 2 lack a palatal constriction, and type 2 also lacks a pharyngeal constriction, as does type 8 .

Delattre and Freeman's study laid groundwork for the understanding of articulatory variation in English $/ \mathrm{x} /$, but the eight $\mathrm{x}$-ray tracings in Fig. 1 are exemplars of categories and not clearly useful as prototypes. It is easy to overinterpret them. For example, the angle of the tongue tip is a very salient difference between the prototypes for 7 and 8 , but the crucial difference that these two tracings were meant to demonstrate is the pharyngeal constriction that is present in (American) type 7 and absent in (British) type 8. We do not expect these eight examples to exhaustively represent the range of tongue shapes used for English / $\mathbf{x}$ / (see also Westbury et al. 1998:221), and certainly the timing of the gestures involved is not represented by these snapshots. In a study of Canadian English, Campbell and colleagues (2010) found that the timing of these constrictions in prevocalic $/ \mathrm{x} /$ is front to back (labial, palatal, then pharyngeal), while in postvocalic $/ \mathrm{x} /$ the pharyngeal and labial constrictions are simultaneous and followed by the palatal constriction.

Much of the work on $/ \mathrm{x} /$ has been cast in terms of two $/ \mathrm{x} /$ types, broadly described as bunched and retroflex. Many individuals do indeed exhibit clearly categorical variation between tip-down (types 3-4) and tip-up (types 7-8) / $\mathbf{x} /$ types. The status of blade-up (as opposed to tip-up/retroflex) $/ \mathrm{x} / \mathrm{s}$ with respect to these two categories is unclear, if such a status is even relevant. Hagiwara (1995) proposes that blade-up / $/ \mathbf{I}$ (types 5-6) is more similar to bunched than to retroflex, and others have associated it with retroflex $/ \mathrm{x} /$ because they both involve tip/blade raising. We review the literature on intraspeaker variation in terms of a binary distinction, and revisit the necessarily speaker-specific nature of the distinction below in $\S 3$.

in our phonological analysis we argue that $[\tau]$ is the default (if not most frequent) allophone for most speakers with variation between the two.

${ }^{2}$ Delattre and Freeman's images have been flipped horizontally to conform with conventions for the orientation of midsagittal ultrasound images of the vocal tract. 
2.1. REPORTED / $/$ /-ALLOPHONY PATTERnS. While some speakers either bunch or retroflex exclusively, intraspeaker variation in $/ \mathbf{x} /$ tongue shape is well documented. These studies show that $/ \mathrm{I} /$ is more likely to be retroflex when it is prevocalic, in the context of back and/or low vowels, or not in the context of lingual consonants.

Delattre and Freeman's cineradiographic study included three British and forty-three American English speakers pooled within regions and within broad segmental and prosodic contexts. Each speaker produced thirty-two words, and the most salient difference observed in them is between prevocalic and postvocalic contexts. All groups of speakers who produced any retroflex $/ \mathrm{x} / \mathrm{s}$ have higher rates of retroflexion prevocalically than postvocalically. An earlier palatography study by Uldall (1958), based on her own speech, found that syllabic/ $/ \mathbf{I}$ / was bunched, and / $\mathbf{x} /$ was retroflex when in prevocalic position or in postvocalic position next to a coronal consonant. Together, these works suggest a preference for retroflexion in prevocalic position over postvocalic position.

Delattre and Freeman (1968:60-61) further observe that consonant place of articulation affects retroflexion rate, specifically that a preceding consonant interferes with retroflexion differently depending on its place of articulation. They report that labials interfere the least and velars interfere the most. Westbury and colleagues (1998) report a large-scale study of inter- and intraspeaker variation in $/ \mathrm{x} /$ production, using pointtracking data from five $/ \mathrm{I} /$-containing words in the X-ray Microbeam Speech Production Database (XRMB-SPD; Westbury 1994). Their fifty-three speakers produced multiple repetitions of the words row, across, problem, street, and right. Angles between the pellets used to track points on the tongue were measured in order to determine the angle of the tongue blade, which is positive for retroflex tongue postures and negative for bunched ones. ${ }^{3}$ The word row shows the most variation and the most retroflexion, and street shows the least. Speakers who retroflex in row invariably show a lower degree of retroflexion in street, and speakers with extreme bunched tongue shapes in row also show less extreme bunching in street. The lack of retroflexion is interpreted as a consequence of the coronal cluster (and the high front vowel), which places more constraints on the tongue-tip position and angle. The / $\mathbf{I} /$ in across has a more bunched shape than row for forty-five of fifty-two speakers. A similar reduction in retroflexion is seen in problem, compared with row, but the magnitude of the difference is smaller. The $/ \mathrm{x} / \mathrm{s}$ in right and row are very similar to each other. Like Delattre and Freeman, Westbury and colleagues (1998:222) conclude that the tongue is freer to retroflex or to make an extreme bunching posture when $/ \mathrm{x} /$ is next to a labial or when there is no consonant present (i.e. in word-initial position). They also observe that the presence of a labial consonant is nevertheless more constraining than the absence of any consonant. Westbury and colleagues (1998) looked for, but did not find, an effect of oral-cavity size on tongue-blade angle during / $/ \mathrm{d}$ production.

Espy-Wilson and Boyce (1994) report point-tracking data produced with electromagnetic midsagittal articulometry (EMMA) from one speaker who bunches next to velars and retroflexes elsewhere. Guenther and colleagues (1999) report EMMA data from seven speakers producing the nonsense words /waıav/, /wabıav/, /wavıav/, /wadıav/, and /wagıav/. Two speakers have essentially bunched tongue shapes for all five words, two have essentially retroflex tongue shapes, and three have variation between the two categories. One of these speakers bunches in /wagıav/ and retroflexes elsewhere, and two bunch in /waguav/ and /waduav/ and retroflex elsewhere. These results are consis-

\footnotetext{
${ }^{3}$ Westbury and colleagues (1998) report the angles and do not directly categorize the / $\mathrm{x} /$ productions; we have reinterpreted the positive angles as retroflex and the negative ones as bunched.
} 
tent with Delattre and Freeman's generalizations involving the relative effects of labials, coronals, and velars, with $/ \mathbf{x} /$ next to labials patterning similarly to $/ \mathbf{x} /$ that is not in a consonant cluster. Similarly, Tiede and colleagues (2011) report that one speaker retroflexes in /auda/ but not /asa/ or /asga/. Aside from Uldall's (1958) self-reported pattern, no other studies have shown retroflexion to be favored by coronals. It is possible that Uldall was actually observing bunched $/ \mathbf{x} /$ with increased blade raising (due to the coronal consonants). Palatography does not reveal other indicators of bunching (such as dorsum concavity) that are useful for making this distinction based on midsagittal images, where it is still a difficult distinction to make for many speakers. Together, these studies suggest a preference for retroflexion in $/ \mathrm{x} /$ adjacent to labial consonants and for bunching in $/ \mathbf{x} /$ adjacent to dorsal consonants. They also suggest a preference for retroflexion in word-initial position, but bunching in consonant clusters.

The effect of vowel context was first rigorously investigated by Ong and Stone (1998), who used ultrasound to examine the effect of vowel context on one speaker who produced bunched and retroflex $/ \mathbf{x} /$, as part of a larger study involving MRI and electropalatography. In intervocalic context, the speaker produced bunched $/ \mathrm{I} /$ when the flanking (identical) vowels were front /i i e $\varepsilon$ æ/, and retroflex / $\mathrm{x} /$ when the vowels were back / u $\cup$ o ว $\Lambda$ a/. Tiede and colleagues (2011) report data from four speakers who produced /aua/, /isi/, and /uxu/ sequences. This study investigated the effects of an appliance designed to affect $/ \mathbf{x} /$ tongue posture. In the baseline condition (before the appliance was inserted), two speakers exclusively bunched, a third speaker retroflexed nine out of ten times in /aua/ and one out of ten times in /uxu/ and otherwise bunched, and the fourth speaker retroflexed one out of ten times in /uxu/ and bunched otherwise. These results are consistent with Ong and Stone's findings, in that retroflexion is observed with back vowels, and they also suggest that /a/ is more conducive to retroflexion than $/ \mathrm{u} /$.

Hagiwara's (1995) investigation of / $\mathbf{x} /$ included a probe-contact study of fifteen speakers in California. Subjects produced initial, syllabic, and final $/ \mathrm{x} /$. Tongue shape was assessed by inserting a cotton swab between the teeth and determining whether it contacted the tongue blade (suggesting bunched $/ \mathrm{x} /$ ), the tongue tip (suggesting bladeraising $/ \mathrm{x} /$ ), or the underside of the tongue (suggesting retroflex $/ \mathrm{x} /$ ). Hagiwara reported that nine speakers produced retroflex $/ \mathbf{x} /$ exclusively, five produced blade-raising $/ \mathbf{I} /$ word-initially and bunched $/ \mathrm{x} /$ elsewhere, and one had the exact opposite pattern. There was little or no variability within each context. These results are somewhat surprising for both the high frequency of retroflexion and the complete lack of observed variation between vowel context/i/vs. /a/ and /æ/, both initially and finally.

Table 1 summarizes the findings involving contexts that are favorable to $/ \mathrm{d} /$ retroflexion. Retroflexion has been reported to be more frequent in strong prosodic positions, particularly the syllable onset (Uldall 1958, Delattre \& Freeman 1968). Retroflexion is most frequent when $/ \mathrm{x} /$ is not in a consonant cluster, and if it is in a cluster, retroflexion is most frequent with labials, followed by coronals and then by dorsals (Delattre \& Freeman 1968, Espy-Wilson \& Boyce 1994, Westbury et al. 1998, Guenther et al. 1999), although findings concerning the relationship between coronals and dorsals are not very consistent. Finally, although the data on the effect of vowel context are sparse, retroflexion appears to be favored by back and perhaps also low vowels (Ong \& Stone 1998, Tiede et al. 2011). ${ }^{4}$ Figure 2 shows the rates of retroflexion found in different contexts by previous

\footnotetext{
${ }^{4}$ See also Lindau 1985 for an acoustic study of American English / $\mathbf{x} /$ and several other kinds of rhotic sounds. Several other articulatory studies do not bear directly on intraspeaker variation (Zawadski \& Kuehn 1980, Kent 1985, Narayanan et al. 1997, Zhou et al. 2008). See also Shriberg and Kent's (1995) discussion.
} 


\begin{tabular}{|c|c|c|c|c|}
\hline STUDY & TYPE & SUBJ. & WORDS & FAVORS RETROFLEXION \\
\hline \multicolumn{5}{|c|}{ SYLLABLE POSITION: PREVOCALIC > POSTVOCALIC } \\
\hline Delattre \& Freeman 1968 & $\mathrm{x}$-ray & 46 & 32 & pre- $\mathrm{V}>$ post- $\mathrm{V}$ \\
\hline Uldall 1958 & palatography & 1 & N/A & pre- $\mathrm{V}>$ post- $\mathrm{V}>$ syl \\
\hline Hagiwara 1995 & probe-contact & 15 & 6 & pre- $\mathrm{V}>$ post-V (blade) \\
\hline \multicolumn{5}{|c|}{ CLUSTERS: WORD-INITIAL > ONSET CLUSTER } \\
\hline Westbury et al. 1998 & microbeam & 53 & 5 & $\#>$ lab $>$ dor $>$ /stui/ \\
\hline Guenther et al. 1999 & EMMA & 7 & 5 & $\#$, lab $>$ cor $>$ dor \\
\hline \multicolumn{5}{|c|}{ ADJACENT CONSONANT: LABIAL > DORSAL } \\
\hline Delattre \& Freeman 1968 & x-ray & 46 & 32 & lab $>$ cor $>$ dor \\
\hline Westbury et al. 1998 & microbeam & 53 & 5 & $\#>$ lab $>$ dor $>$ /stui/ \\
\hline Guenther et al. 1999 & EMMA & 7 & 5 & $\#$, lab $>$ cor $>$ dor \\
\hline Espy-Wilson \& Boyce 1994 & EMMA & 1 & $\mathrm{~N} / \mathrm{A}$ & other $>$ dor \\
\hline Tiede et al. 2011 & MRI & 4 & $3-5$ & cor $>$ other contexts \\
\hline Uldall 1958 & palatography & 1 & N/A & cor $>$ other Cs \\
\hline \multicolumn{5}{|c|}{ ADJACENT VOWEL: BACK/LOW > FRONT } \\
\hline Ong \& Stone 1998 & ultrasound & 1 & 11 & back $>$ front \\
\hline Tiede et al. 2011 & MRI & 4 & $3-5$ & $/ \mathrm{a} />/ \mathrm{u} \mathrm{i} /$ \\
\hline
\end{tabular}

TABLE 1. Findings from previous studies on $/ \mathbf{x} /$ allophony,

studies. Segmental contexts have been adapted somewhat to be comparable with each other and with the results from the experiment in the next section. ${ }^{5}$

2.2. Acoustic/Perceptual Similarity. Whatever way it is articulated, American English $/ \mathbf{I} /$ is characterized by low F1, low F2, and extremely low F3 (Delattre \& Freeman 1968, Narayanan et al. 1997, Boyce \& Espy-Wilson 1997, Westbury et al. 1998). It has not, to our knowledge, been proposed in the literature that the different $/ \mathbf{x} /$ tongue postures are perceptibly different. Delattre and Freeman (1968) report that syllable position and constriction degree (as estimated from lateral x-ray images) both impact the acoustic properties of $/ \mathrm{x} /$, but they found no acoustic consequences of particular tongue postures, consistent with subsequent studies (Westbury et al. 1998, Guenther et al. 1999). Lehiste (1962) reported that initial and 'initial-like' allophones of $/ \mathrm{d} /$ in other contexts have lower F1, F2, and F3 than other /x/ allophones. Zawadski and Kuehn (1980) report that prevocalic $/ \mathbf{x} /$ involves more lip rounding and tongue-body advancement, and less grooving of the tongue dorsum, that postvocalic $/ \mathrm{x} / \mathrm{seems}$ like the second part of a diphthong, and that syllabic $/ \mathbf{x} /$ is similar to postvocalic $/ \mathbf{x} /$. See Espy-Wilson et al. 2000 for further discussion.

\footnotetext{
${ }^{5} \mathrm{M}=$ this study $(n=27) ;\{$ Ds Dm Dn Dp Dy $\}=$ Delattre \& Freeman 1968 South $(n=5)$, Midwest $(n=10)$, New England $(n=5)$, Pacific $(n=20)$, New York $(n=3)$; W = Westbury et al. $1998(n=53$; rates estimated to reflect apparent ordinal ranking); $\mathrm{U}=$ Uldall $1958(n=1) ;\{\mathrm{Ha} \mathrm{Hb}\}=$ Hagiwara $1995(n=9,6) ;\{\mathrm{T} 3 \mathrm{~T} 1$ T2 $\}=$ Tiede et al. $2011(n=1,1,2)$; OS = Ong \& Stone $1998(n=1)$; SK = Shriberg \& Kent $1995(n=$ ?); EB = Espy-Wilson \& Boyce $1994(n=1) ;\{\mathrm{Ga} \mathrm{Gb} \mathrm{Gc} \mathrm{Gd}\}=$ Guenther et al. $1999(n=2,1,2,2) ;\{\mathrm{Za} \mathrm{Zb}\}=$ Zhou et al. $2008(n=1,1)$. For Uldall 1958, /\#.ı \#.ıo \#.xi/ represent the 'Initial' category, /a.t o.tt aut $\int$ o.t5/ represent the 'Final with s,S,c,d' category, and /aı\# ox\# axp oxp auf oxf axk ouk ir\#/ represent the 'Final other' category. The syllabic category is not included. For Delattre \& Freeman 1968, /\#.ла \#.ı \#.іi/ represent the words in the 'Initial' category, /pıa kıa kıo tıa kıi/ represent the words in the 'Postconsonantal category', /asp a.t a.sk/ represent the words in the 'Preconsonantal' category, and /aı\# ol\#/ represent the words in the 'Final' category. The 'Intervocalic pre-stress' and 'Intervocalic post-stress' categories are not included. For Hagiwara 1995,

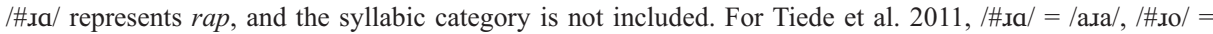

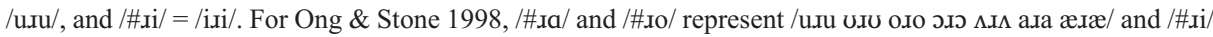

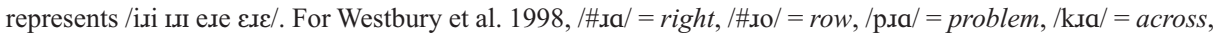
/tui/ = street. For Shriberg \& Kent 1995, /pıa/ and /pıi/ represent /pıV/ with low-back and high-front vowels, respectively. For Espy-Wilson \& Boyce 1994, Guenther et al. 1999, and Zhou et al. 2008, /\#ıa/ = /wasav/, /pıa/ represents /wabıav/ and /wavıav/, /kıa/ =/wagıav/, and /tıa/=/wadıav/.
} 


\section{Retroflexion rate by subject and context}

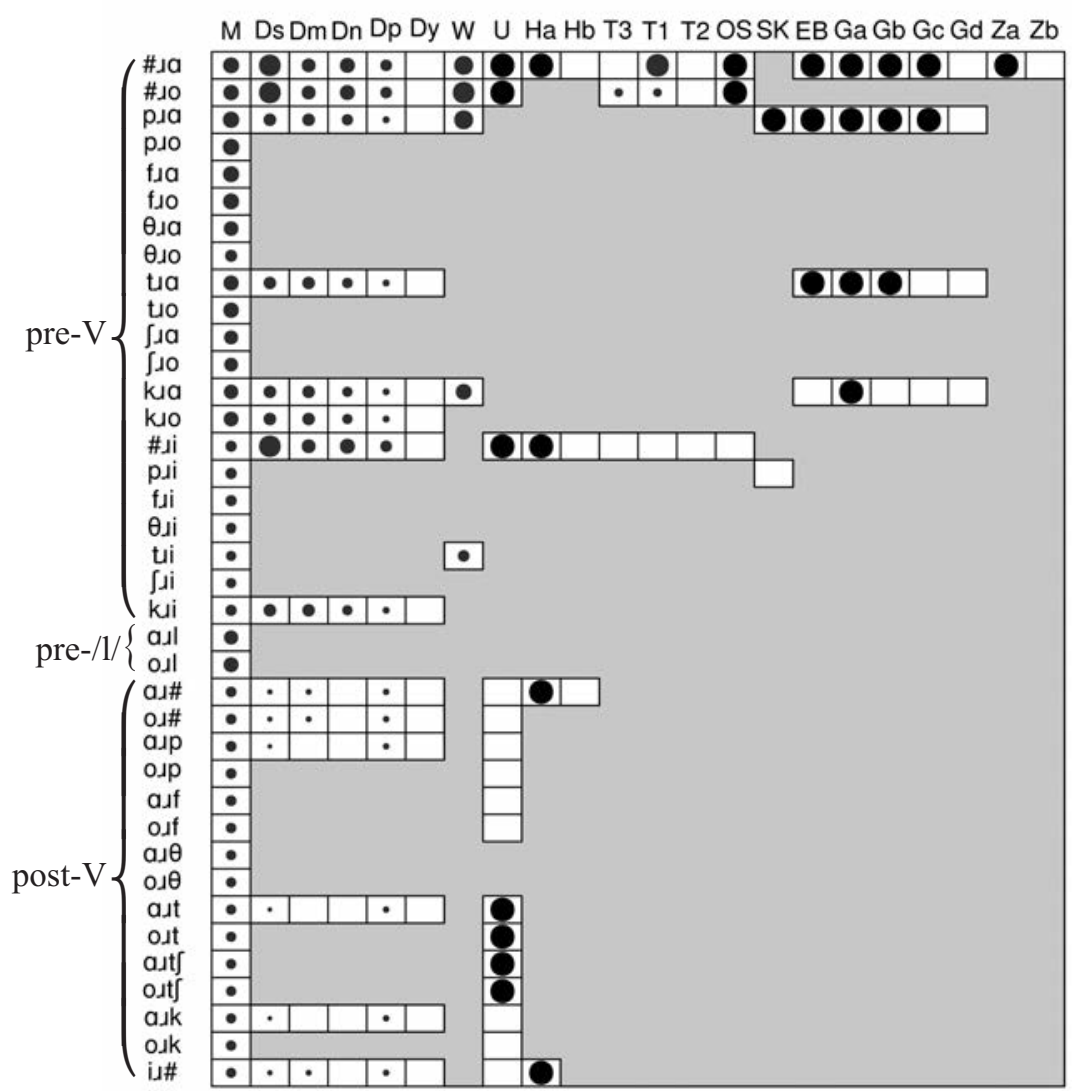

FIGURE 2. Retroflexion rates for prevocalic and postvocalic $/ \mathrm{x} /$ reported in the literature. Gray indicates contexts that were not examined. See n. 5 about contexts.

Espy-Wilson and Boyce (1994) report that F3 and F4 are closer together in bunched $/ \mathrm{A} /$ than in retroflex $/ \mathbf{x} /$ for a speaker who bunches next to velars and retroflexes elsewhere. More recently, Zhou and colleagues (2008) argue on the basis of three speakers who produce bunched $/ \mathbf{I} /$ and three speakers who produce retroflex $/ \mathbf{I} /$ that a consistent acoustic difference between the two is that F4 and F5 are farther apart in retroflex / $/$ / than in bunched / $\mathrm{x} /$. Based on acoustic modeling, Zhou and colleagues (2008:4478) conclude that F3, F4, and F5 are all back-cavity resonances in bunched and retroflex /x/, but that these are half-wavelength resonances for retroflex $/ \mathbf{I} /$ and quarter-wavelength resonances for bunched $/ \mathrm{x} /$. The significance of this result is that the bunched and retroflex $/ \mathrm{x} / \mathrm{s}$ observed by Zhou and colleagues are not simply two different ways to make the same vocal-tract shape, but rather they involve distinct vocal-tract shapes that produce similar acoustic consequences by different mechanisms, and both are distinct from Stevens's (1999) sublingual-resonance account of /I/'s low F3. See Zhou 2009 for a more detailed discussion of acoustic modeling of $/ \mathrm{x} /$ and $/ \mathrm{l} /$.

These studies indicate that F4 and F5 provide potential acoustic cues to / $\mathrm{x} /$ tongue shape, and the modeling suggests that these differences could be stable across a population of speakers. Espy-Wilson and Boyce's findings involving F3 and F4 were not repli- 
cated, suggesting that this may be an idiosyncratic acoustic difference. Differences involving F4 and F5, even if stable, may not contribute to listeners' ability to distinguish $/ \mathbf{x} /$ allophones, because, as Zhou and colleagues (2008:4467) observe, 'the process of speech perception appears to largely depend on the pattern of the first three formants' ${ }^{6}$ Differences involving F3 are more likely to be detected by listeners, but if they vary between individuals, they do not provide reliable cues about tongue shape to a language learner. A perception study by Twist and colleagues (2007) indicates that subjects are mildly successful with distinguishing prevocalic and postvocalic $/ \mathrm{x} / \mathrm{s}$, but dismal at distinguishing bunched and retroflex $/ \mathrm{x} / \mathrm{s}$, consistent with previous findings that the acoustic properties of $/ \mathbf{x} /$ are more greatly affected by syllable position.

It is possible that speakers can detect acoustic differences between bunched and retroflex $/ \mathrm{s} / \mathrm{s}$, and it would be valuable to explore whether listeners make use of intrinsic acoustic differences between $/ \mathbf{I} /$ types or their coarticulatory effects, perhaps for purposes of speaker identification. Nevertheless, the information that is available to us from the research that has been conducted on the acoustic differences between $/ \mathbf{x} /$ types and their perceptibility leads us to believe that speakers are not sensitive to each other's $/ \mathrm{I} /$-allophony patterns. This contrasts with other rhotics that have been studied articulatorily, such as French /R/ (Delattre 1969), where aerodynamics and the perceptibility of deviations limit articulatory variation, and Scottish English and Dutch /r/ (Scobbie et al. 2006), which show considerable perceptible variation.

Any regional variation in English $/ \mathbf{x} /$ tongue shape would suggest either that the difference between $/ \mathbf{x} /$ allophones CAN be perceived, or that $/ \mathbf{x} /$ allophony is being conditioned by some other (regionally varying) variable, which is itself perceptible. r-less varieties of English such as those found in Southern England and the northeastern United States are expected to differ articulatorily from $r$-ful varieties, but differences among r-ful American English varieties are surprising. Delattre and Freeman (1968) intended their study as a first attempt at mapping dialect variation in $/ \mathrm{I} /$ tongue shape, to be further investigated by follow-up dialectology work on $/ \mathrm{x} /$ tongue posture, which to our knowledge has not occurred. They were very cautious about interpreting their apparent regional differences. Some of their observations (such as the observation that type 4 is not used by women) have been contradicted by subsequent research, and others remain to be tested.

One reason why the large-scale dialect studies have not been conducted is that finding statistically significant tongue-shape variation between varieties whose $/ \mathrm{x} / \mathrm{s}$ sound the same seems very unlikely. Further, the subsequent studies, which have involved large numbers of speakers, have not found further evidence of dialect variation. Westbury and colleagues (1998:224) comment that:

[t]ongue shapes for $/ \mathrm{I} /$ produced by the 28 sons and daughters of Wisconsin in the study sample, whom we might expect to speak the same dialect, were not distributed in any plane slice, through any of the shape spaces considered, in a way that was especially different from the distribution of tongue shapes of 11 (of the remaining 25) speakers who were neither Wisconsinites, nor Upper Midwesterners.

Tongue-shape variation could occur due to other types of variation that impact $/ \mathrm{x} /$, or due to the impact of $/ \mathbf{x} /$ tongue shape on the production of adjacent sounds. For example, we have previously discussed potential consequences of $/ \mathrm{x} /$ tongue posture on the centroid frequency of a nearby sibilant in /sti/ clusters (Mielke et al. 2010, Baker et al.

\footnotetext{
${ }^{6}$ For example, Warner and colleagues (2009) found only a very small perceptual effect of a large (1000 Hz) dip in F4 in a perceptual study of English flaps.
} 
2011). But for the most part the relationships between $/ \mathrm{A} /$ variants and the acoustic properties of adjacent sounds have not been worked out. We return to the topic of looking for dialect variation in the discussion.

2.3. REASONS FOR ARTICULATORY VARIABILITY. Because of the wide variety of $/ \mathbf{x} /$ tongue postures that may be used to achieve similar acoustic results, English $/ \mathrm{d} / \mathrm{has}$ been used as a laboratory for studying articulatory trading relations. Since such a large region of articulatory space maps onto such a small region of acoustic space, $/ \mathbf{I} / \mathrm{al}$ lophony is potentially very informative about how and why speakers select between alternative articulations. Bunching is favored in contexts involving dorsal consonants and high front vowels, both of which, like bunched /x/, are produced with a bunched tongue shape and a dorsal constriction. The preference for bunching in this context appears to be due to articulatory similarity between the / $\mathrm{d} /$ type and the segmental context.

Guenther and colleagues (1999) argue that articulatory variability serves the function of reducing acoustic variability. Low F3, the most important cue to /x/, can be achieved by increasing the palatal-constriction length, by increasing the front-cavity length, and by decreasing the constriction area. Since the acoustic cue can be enhanced by changing the vocal-tract shape in three different ways, speakers can exploit trading relations between them. If the phonetic context makes one of these more difficult, acoustic stability can be achieved by enhancing the others. For example, a velar stop requires the tongue body to be high, and requires a speaker to manipulate the other two options in order to achieve the right acoustic target. In their EMMA study, Guenther and colleagues found that all seven speakers showed the expected positive correlation between tongue-back height and tongue-front horizontal position. Five of these also showed the expected negative correlation between tongue-back height and tongue-front height. This includes three subjects with bunched vs. retroflex variation and two subjects with only bunched tongue shapes. One of the retroflexers instead showed the expected positive correlation between tongue-front horizontal position and tongue-front height. The other retroflexer only showed the first expected correlation. They observe that the $/ \mathrm{x} /$ tongue postures resemble the tongue postures required for adjacent sounds. For example, the tongue shape used for $/ \mathrm{g} /$ is very similar to the tongue shape used for $/ \mathrm{J} /$ in that context.

Matthies and colleagues (2008) found that postlingually deaf individuals exhibit more acoustic variability in $/ \mathrm{x} / \mathrm{s}$ across segmental contexts, but that one year with auditory feedback from cochlear implants decreases the variability significantly. This indicates that auditory feedback is necessary in order to produce an $/ \mathrm{x} /$ that is acoustically stable across contexts. Tiede and colleagues (2011) found that speakers adjust their tongue posture in response to an appliance that disrupts normal $/ \mathbf{x} /$ production. After insertion of a palatal prosthesis that effectively increased the size of the alveolar ridge by $6 \mathrm{~mm}$, three of four subjects responded by increasing their rate of retroflexion in the same segmental contexts, including one subject who did not produce any retroflex $/ \mathrm{d} / \mathrm{s}$ prior to insertion of the appliance. Derrick and Gick $(2008,2011)$ showed that English speakers vary between upward and downward flap and tap gestures depending on where the tongue tip needs to be for neighboring sounds, and speakers change their strategies in response to recent speech errors.

While a lot is known about the effect of prosodic position on the choice of $/ \mathrm{x} /$ tongue posture, and how and why certain consonants affect $/ \mathbf{x} /$ choice, less is known about the role of vowels and about how the different factors interact. Studies that show that front vowels are more favorable to bunching and back vowels are more favorable to retroflexion are based on a small number of subjects. While this pattern would be consistent with 
an articulatory explanation, other studies apparently show no effect of vowel context. It is clear from several studies that lingual consonants inhibit retroflex $/ \mathrm{x} /$ production, but less is known about the relative effects of coronal and dorsal consonants, and the effect of a labial consonant as opposed to the absence of a consonant. Since most of the studies reported only a small range of contexts, little is known about how the different factors interact with each other (i.e. if linguals and front vowels favor bunching, what happens between a lingual and a back vowel or between a labial and a front vowel?), and since most of the studies investigated a small number of contexts or a small number of subjects or pooled the results, little is known about individual $/ \mathbf{I} /$-allophony patterns. In order to investigate these areas further, we conducted an ultrasound study of $/ \mathbf{x} /$ tongue postures for a group of American English speakers.

3. EXPERIMENT. The experiment was designed to explore the tongue postures used by individuals across a range of phonological contexts and across multiple repetitions. Ultrasound is useful for this purpose because it is safe and noninvasive, enabling the rapid acquisition of a large amount of articulatory data from a large number of subjects. Each subject read 441 words with $/ \mathrm{x} / \mathrm{s}$ or $/ 2 \%$, plus filler words, an activity that took about twenty minutes.

3.1. Methods. Ultrasound video, camera video, and audio recordings were generated while subjects produced English words. Monosyllabic real-word stimuli were elicited in the carrier phrase 'Please say _ again'. Stimuli were selected so that $/ \mathrm{x} / \mathrm{s} \mathrm{oc-}$ curred before or after one of the three vowels $/ \mathrm{a}$ o $\mathrm{i} /$; some $/ \mathrm{x} / \mathrm{s}$ were in word-initial or word-final position, while others were separated from the word edge by one of the consonants /p t k f t $\int \theta$ 1/. /o/ was used instead of /u/ because American English /u/ is often fronted, with a tongue posture not very different from that of $/ \mathrm{i} /$. Three words were selected for each of the phonotactically permissible contexts involving these segments, with the exception of the six word-initial and word-final contexts, which had five words each, and $/ \int \mathrm{sa} /, / \int \mathrm{xo} /$, and /oxl/, which had two words each, due to a lack of words. No /isC\#/ contexts were included, due to phonotactic restrictions. Words with syllabic / $\mathrm{I} /$ $\left(/ \mathrm{a}^{\mathrm{r}} /\right)$ are reported in Appendix A and not discussed further. In all, 147 target words and thirty-three filler words were repeated by the subjects three times. The stimuli are listed in Appendix B.

Twenty-seven native speakers of American English whose tongues were easily imaged by ultrasound participated in the study. ${ }^{7}$ All were University of Arizona undergraduate students aged eighteen to twenty-four (fifteen females and twelve males). Their information is given in Table 2, along with a preliminary categorization of their $/ \mathrm{A} /$ productions. $^{8}$

A SonoSite TITAN portable ultrasound unit was used to generate real-time ultrasound video of the tongue at a rate of twenty-eight scans per second, output as $29.97 \mathrm{fps}$ NTSC video. ${ }^{9}$ Audio recordings were created using a condenser microphone mounted

\footnotetext{
${ }^{7}$ One additional participant was excluded due to poor imaging.

${ }^{8}$ Note that some of our /a/ words actually include / $/$ / for speakers who have a contrast between /a/ and / $/$. Eight participants have lived in places where a phonemic contrast between /a/ and / $/$ is expected: $r 18, r 22$, r31 (bunched); r01, r17, r27 (variable); and r13, r30 (retroflex). It is conceivable that some of the variability in r01's, r17's, and r27's words with /a/ could be accounted for by a vowel difference.

${ }^{9}$ A two-dimensional (B-mode) ultrasound image made with a convex array transducer is generated by scanning radially. In this experiment, the transducer was oriented so that each scan started at the most anterior (right) edge of the image. When a scan completes, the information on the right edge of the image is $35.7 \mathrm{~ms}$ old. A video frame is generated every $33.4 \mathrm{~ms}$, so there is a small amount of overlap between consecutive images: the oldest part of each image (a thin slice that is just ahead of the current scan, that is, 2.3 ms worth
} 


\begin{tabular}{|c|c|c|c|c|c|}
\hline CODE & AGE & SEX & PLACES & OTHER LANGUAGES & /ג/ CODING \\
\hline $\mathrm{r} 03$ & 18 & $\mathrm{~F}$ & AZ, HI, Japan & & bunched \\
\hline r05 & 18 & $\mathrm{~F}$ & AZ, Mexico & Spanish & bunched \\
\hline r07 & 24 & $\mathrm{M}$ & $\mathrm{AZ}$ & ASL & bunched \\
\hline r11 & 18 & M & $\mathrm{AZ}$ & & bunched \\
\hline $\mathrm{r} 15$ & 22 & $\mathrm{~F}$ & $\mathrm{AZ}$ & & bunched \\
\hline $\mathrm{r} 16$ & 20 & $\mathrm{M}$ & $\mathrm{AZ}$ & & bunched \\
\hline $\mathrm{r} 18$ & 18 & $\mathrm{~F}$ & $\mathrm{AZ}, \mathrm{MI}$ & & bunched \\
\hline $\mathrm{r} 20$ & 18 & $\mathrm{~F}$ & ID & & bunched \\
\hline $\mathrm{r} 21$ & 18 & $\mathrm{~F}$ & $\mathrm{AZ}$ & Urdu & bunched \\
\hline r22 & 18 & M & $\mathrm{CA}, \mathrm{SD}, \mathrm{WA}$ & French & bunched \\
\hline $\mathrm{r} 23$ & 21 & M & $\mathrm{AZ}, \mathrm{ME}$ & & bunched \\
\hline $\mathrm{r} 25$ & 18 & M & $\mathrm{CA}$ & & bunched \\
\hline r26 & 20 & M & $\mathrm{AZ}$ & & bunched \\
\hline $\mathrm{r} 28$ & 18 & F & $\mathrm{AZ}, \mathrm{SD}$ & & bunched \\
\hline r29 & 19 & M & $\mathrm{AZ}$ & & bunched \\
\hline r31 & 18 & $\mathrm{~F}$ & NJ & & bunched \\
\hline r01 & 19 & $\mathrm{~F}$ & IN & & bunched \& retroflex \\
\hline r04 & 18 & $\mathrm{~F}$ & WA, CA & & bunched \& retroflex \\
\hline r06 & 18 & $\mathrm{~F}$ & $\mathrm{CA}$ & & bunched \& retroflex \\
\hline $\mathrm{r} 08$ & 18 & $\mathrm{~F}$ & $\mathrm{AZ}$ & Navajo & bunched \& retroflex \\
\hline $\mathrm{r} 10$ & 19 & $\mathrm{M}$ & $\mathrm{AZ}$ & & bunched \& retroflex \\
\hline r17 & 18 & $\mathrm{M}$ & AZ, WI & & bunched \& retroflex \\
\hline r19 & 21 & $\mathrm{M}$ & $\mathrm{AZ}$ & Spanish & bunched \& retroflex \\
\hline r27 & 19 & $\mathrm{M}$ & AZ, IA & & bunched \& retroflex \\
\hline r32 & 18 & $\mathrm{~F}$ & $\mathrm{AZ}, \mathrm{NM}$ & & bunched \& retroflex \\
\hline r13 & 18 & $\mathrm{~F}$ & WI & Kannada, Telugu & $\overline{\text { retroflex }}$ \\
\hline $\mathrm{r} 30$ & 19 & F & GA, Germany & German & retroflex \\
\hline
\end{tabular}

TABLE 2. The twenty-seven subjects, divided into three categories according to observed tongue postures.

close to the subject's mouth, and video of the subject's head in profile was created using a camcorder.

3.2. Data AnAlysis. Each $/ \mathrm{x} /$ token was coded for tongue posture. The purpose of this classification is to establish whether each speaker had a categorical split between tip/blade-up $/ \mathbf{x} /$ and tip/blade-down $/ \mathbf{x} /$, and if so, to determine the contexts for each variant. An assortment of qualitative and quantitative techniques were used in order to ensure that this classification was performed properly for each speaker. Following Westbury and colleagues (1998), we did not expect each speaker's $/ \mathbf{x} / \mathrm{s}$ to fall neatly into Delattre and Freeman's categories, but we used their templates as a tool for an initial classification. While we expect gradient variability across contexts, the best motivation behind our expectation that a speaker's productions of $/ \mathbf{x} /$ could fall into one or both of the tip-up and tip-down categories is Zhou and colleague's (2008) finding of two different modes of achieving the low F3, associated with bunched and retroflex speakers. Having said this, we have no reason to rule out the possibility of three or more distinct categories, or speakers with substantial articulatory variation that is not amenable to

of scanning, or about $5 \%$ of the image) is the same as the newest part of the previous image. Whenever a video frame is created while the scan line is passing through a fast-moving part of the tongue, the scan line is visible as a 'seam' between the old and new parts of the image. This is a concern for studies requiring precise timing information involving different places in the ultrasound images, but mostly inconsequential for this study, because the gestures involved in / $\mathbf{x} /$ production are typically much longer than $33 \mathrm{~ms}$ and span multiple video frames. 
categorization. We report the variability we found, and discuss what posed the greatest challenge to these methods.

We are primarily interested in a categorical distinction between $/ \mathrm{x} /$ types that are produced with increased raising of the tongue tip or blade relative to other $/ \mathrm{x} / \mathrm{s}$ produced by the same speaker, and this necessarily boils down to intraspeaker comparisons. Delattre and Freeman's eight $/ \mathbf{x} /$ types are examples of the range of variation in their sample of speakers, rather than prototypes for studying intraspeaker variation. However, a speaker who only produces $/ \mathrm{I} / \mathrm{s}$ resembling types $1-4$ is easy to label as 'bunched', and a speaker who only produces $/ \mathrm{x} / \mathrm{s}$ resembling types $7-8$ is easy to label as 'retroflex'. The primary feature of an $/ \mathrm{I} /$ for our purposes is the angle of the tongue blade; secondarily, we used features that are often observed in tip-down bunched $/ \mathrm{I} / \mathrm{s}$, such as tongue-dorsum concavity. The biggest challenges to binary classification are tongue shapes with intermediate tongue-blade angles, such as those shown in Delattre and Freeman's types $5-6$, or $/ \mathrm{I} / \mathrm{s}$ produced next to a coronal consonant. For a speaker producing $/ \mathrm{J} / \mathrm{s}$ like these, our focus shifted to whether that speaker produced other $/ \mathrm{s} / \mathrm{s}$ with a more clearly bunched or more clearly retroflex tongue posture.

For the initial classification, a video frame was selected at the peak of the $/ \mathrm{x} /$ gesture (based on the movement of the tongue root, tongue body or tip, and the lips). The gestures identifiable as $/ \mathbf{x} /$ typically spanned at least two frames. While it was helpful to be able to focus on one representative frame per token, inspecting the preceding and following frames was crucial for the analysis of many of the speakers' productions. Each token was labeled as bunched, retroflex, or ambiguous. Speakers who produced $/ \mathrm{x} / \mathrm{con}-$ sistently and unambiguously with the same type of tongue shape required no further analysis. $/ \mathrm{I} / \mathrm{s}$ that were initially classified as ambiguous were subsequently grouped with a category with the help of quantitative techniques described below.

In ultrasound images of the tongue, the tongue appears as a dark region, bordered on the top by a lighter region resulting from the scattering of ultrasound waves at the tongue-air interface. This dark-light contrast is often enhanced by image filtering. Typically, the process of finding midsagittal tongue contours in midsagittal ultrasound images involves identifying the lower edge of the white region. In some cases it is more complicated than this. For instance, the tongue is deeply grooved during bunched $/ \mathrm{x} /$, and the vocal-tract slice imaged by ultrasound is about $5 \mathrm{~mm}$ thick. Slight deviations from the midsagittal plane (by either the transducer or the tongue) can result in images showing both the midsagittal groove and one of the sides of the tongue. The researcher chooses the correct edge to interpret in this situation. Ultrasound frames that are ambiguous on their own can often be interpreted by consulting preceding and following frames and narrowing down the range of possible tongue surfaces by considering tongue motion. Consulting adjacent frames is also relevant for locating the tongue tip, which sometimes appears as the most anterior point in the apparent tongue contour, and other times is cut off due to a sublingual air pocket or the shadow of the mandible. When the tongue tip is obscured, the angle of the tongue blade is often still apparent in the image itself, and its orientation is often revealed in movement into and out of the $/ \mathrm{x} /$ gesture. See Stone 2005 for an excellent guide to the process of interpreting ultrasound images of the tongue.

A further set of quantitative techniques was used to help validate template matching. EigenTongues decomposition (Hueber et al. 2007) was used to directly quantify differences between bunched and retroflex tongue shapes in different contexts. The way we have applied this method for speech analysis is described in detail by Carignan and colleagues (2016), and the basic implication here is that it is an extra tool to enhance the re- 
searcher's ability to categorize tokens of $/ \mathrm{x} /$. Template matching has been widely used in the study of American English $/ \mathbf{x} /$, and this quantitative component provides a link between qualitative ultrasound studies and past and future quantitative approaches that seek to go beyond template matching.

EigenTongues decomposition consists of a PRINCIPAL COMPONENT ANALYSIS performed on the pixels in a region of interest in each of a set of ultrasound images that have been filtered in order to enhance the tongue contour. Before processing, images were corrected for head movement using the Palatron system (Baker 2005, Mielke et al. 2005). The first ten principal components (representing independent axes of variance in the tongue positions across all of the phones in the target words) are retained as inputs into LINEAR DISCRIMINANT ANALYSIS (Pouplier \& Hoole 2013) with classes based on place of articulation. The result is a time-varying representation of the degree to which the imaged vocal tract matches several articulatory configurations, with a temporal resolution of $30 \mathrm{~Hz}^{10}$

This analysis included single frames as well as image sequences. The sound files were segmented at the phone level using the Penn Phonetics Lab Forced Aligner (P2FA; Yuan \& Liberman 2008), and representative frames were selected on the basis of this segmentation. Frame sequences included every video frame during the word interval, plus four frames $(\sim 133 \mathrm{~ms})$ before and after. Likely target frames were selected on the basis of a sample of tokens: for $/ \mathrm{x} /$ in most contexts the initial frame representing the peak of the $/ \mathrm{x} /$ gestures was the middle frame of the $/ \mathrm{x} /$ interval, but for $/ \mathrm{I} /$ after noncoronal stops $/ \mathrm{p} \mathrm{k} /$, the peak $/ \mathrm{d} /$ gesture was typically found in the last frame of the stop interval (during the aspiration, which is segmented as part of the stop but could be analyzed as voiceless $/ \mathrm{x} /$ ), and for $/ \mathrm{x} /$ after other consonants $/ \mathrm{f} \theta \int \mathrm{t} /$, the initial target frame was the first frame of the $/ \mathbf{x} /$ interval.

The quantitative approach helped to validate template matching as follows: (i) Plotting tokens by the linear discriminant functions associated with $/ \mathbf{x}$ / types allows apparent outliers to be scrutinized. (ii) A subject's data can be summarized by averaging the images created by reassembling the principal component loadings in the proportions indicated by the principal components. (iii) Tongue movement can be visualized as trajectories through low-dimensional space or as reconstructed videos. The videos for many tokens can be viewed simultaneously in order to assess gestural similarities between repetitions of the same sequences that may look different in an analysis based on single frames. Figure 3 shows the average filtered target frames for a representative group of subjects. Regions where the tongue surface frequently occurs appear bright in these images. The tongue tips are on the right, and some instances where the tip is retroflexed (observe r19 and r30) are apparent from scattering ultrasound waves that produce a bright region above where the tip is expected to occur. On the left are three

${ }^{10}$ This technique is most useful for investigating ambiguous tokens, which mostly means $/ \mathbf{x} / \mathrm{s}$ produced next to lingual consonants. It was used to validate the data from all eleven speakers initially coded as categorically variable and producing retroflex /x/s next to lingual consonants, as well as five speakers coded as producing only bunched or retroflex / $\mathbf{I} /$. It was not necessary to validate the two speakers who produced only retroflex $/ \mathbf{I} /$ in labial contexts (since these were unambiguous) or to validate the rest of the speakers initially coded as not categorically variable. Two speakers who were classified as variable in the initial template-matching step (r22 and r26) were reclassified as noncategorically bunching, but with substantial blade raising. The summary image for $\mathrm{r} 26$ in Fig. 3 illustrates this well: he produces $/ \mathrm{x} /$ with blade raising and dorsum concavity. Template matching of isolated tokens led to some being coded as retroflex and others being coded as bunched, but viewed in the aggregate, it is clear that his tongue postures are very similar across all contexts. 
subjects classified as producing all of their $/ \mathrm{x} / \mathrm{s}$ with a single tongue posture. On the right side of the figure are three subjects who are categorically variable, and their images have been separated according to how they were coded. All three produce clear concavity in their tip-down/bunched $/ \mathrm{d} / \mathrm{s}$, and raise the tip in other contexts.
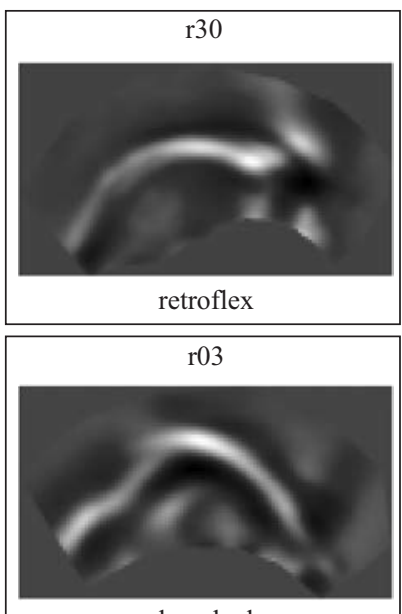

bunched

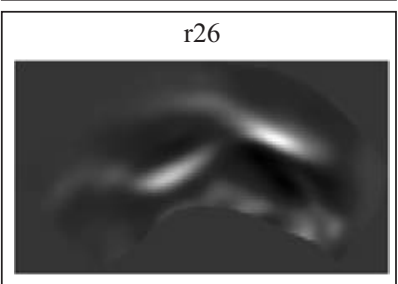

bunched (blade raised)

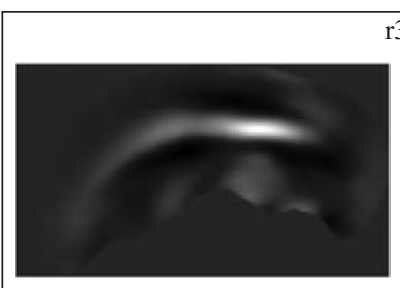

retroflex

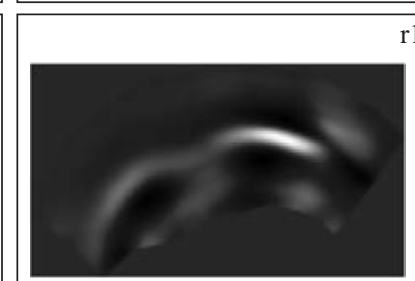

retroflex

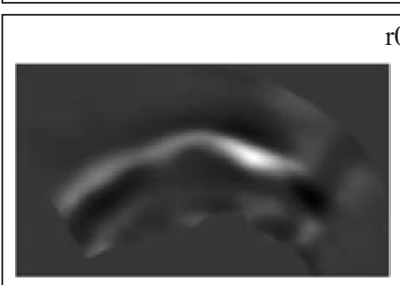

retroflex r32

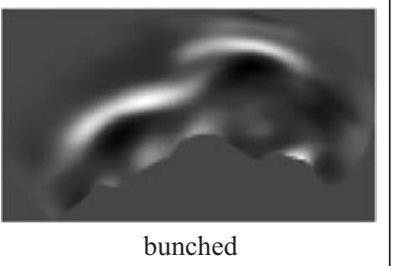

r19

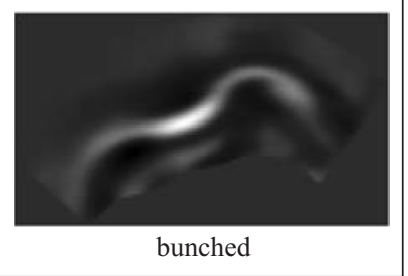

r08

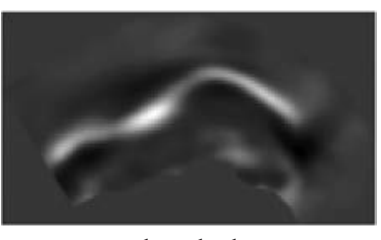

bunched

FIGURE 3. Sample / $\mathbf{I} /$ tongue shapes (averaged filtered ultrasound frames) for three subjects with one consistent tongue shape and three with categorical allophony.

The criteria for classifying / $\mathbf{x} /$ tokens are as follows: unambiguously tip-up articulations (e.g. r30 as shown in Fig. 3) are retroflex, and unambiguously tip-down articulations (e.g. r03, and r19's bunched) are bunched. Tongue-dorsum concavity, which often cooccurs with tip-down $/ \mathrm{x} /$, was used as a secondary indicator of bunching. Many tokens, such as those produced by $\mathrm{r} 26$, are ambiguous with respect to tongue-tip or -blade angle. $r 26$ is classified as bunched on the basis of the strong dorsum concavity, but this choice is mostly moot for our purposes, because he does not vary between this and a categorically different tongue shape. If the definition of retroflexion were expanded to include blade-raising $/ \mathrm{x} / \mathrm{s}$ like $\mathrm{r} 26$ 's, the total number of retroflex/blade speakers would increase, but the picture of $/ \mathrm{x} /$ allophony (our main concern) would be unaffected. For speakers with categorical variation, two more sets of criteria were used: if the speaker uses two different $/ \mathbf{I} /$ types that differ in tongue-blade angle, one is classified as bunched and one is classified as retroflex. r08's bunched $/ \mathrm{x} /$ has a higher blade angle than a lot of other speakers' bunched $/ \mathrm{x} / \mathrm{s}$, but it clearly lacks the tip raising found in her retroflex tokens. The most challenging tokens to classify are $/ \mathrm{x} / \mathrm{s}$ occurring next to lingual consonants, where the distinguishing features of bunched and/or retroflexed postures are both reduced, sometimes to the point of being indistinguishable. A case could 
be made for abandoning the bunched/retroflex distinction in these contexts for some speakers, and we hope that future quantitative studies in the spirit of Westbury and colleagues (1998) and perhaps using new tools such as EigenTongues will shed light on this. In an effort to classify these in the same way as the other tokens, we focused on tip/ blade raising that could not easily be interpreted as part of an adjacent consonant (such as blade raising to a distinct target) and dorsum concavity that could not easily be interpreted as a secondary consequence of other gestures. Video sequences were extremely helpful for recognizing similarities between the gestures involved in these ambiguous tokens and the less ambiguous examples of either category.

3.3. General Results. Out of the twenty-seven subjects in the study, two produced only retroflex $/ \mathbf{I} /$, sixteen produced only bunched $/ \mathbf{I} /$, and nine varied categorically between $/ \mathrm{x} /$ types. As detailed above in Table 1 , the following three asymmetries are expected.

(1) Summary of asymmetries in preference for retroflexion

a. Prevocalic syllable-initial $>$ prevocalic in onset cluster $>$ postvocalic

b. Labial cluster $>$ coronal cluster $>$ dorsal cluster

c. Next to back and/or low vowels $>$ next to front vowels

Figure 4 summarizes the retroflexion rates for the nine speakers in our study who exhibited variation between bunched and retroflex $/ \mathrm{x} /$. The expected effects of syllable position and vowel context are clearly borne out in our data.
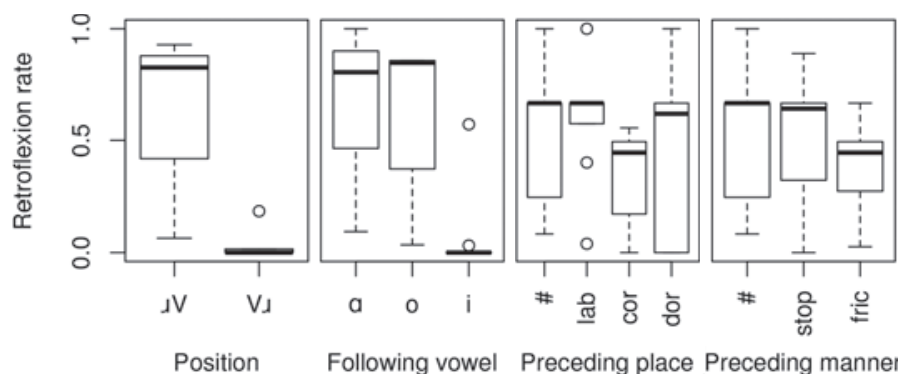

Following vowel Preceding place Preceding manner

FIGURE 4. Prevocalic/x/ retroflexion rate by context for nine subjects with allophony.

A series of linear mixed-effects regressions were performed, each with these nine speakers' retroflexion rates in each segmental context as the dependent variable, speaker as a random factor, and a fixed factor corresponding to one of the boxplots. Tukey posthoc tests were used for pairwise comparisons where applicable. Retroflexion is significantly less frequent postvocalically than prevocalically (estimate $=-0.61993$, $z=-17.73, p<0.0001) .{ }^{11}$ The quality of the following vowel has a significant effect on retroflexion as well, with $/ \mathrm{i} /$ conditioning less retroflexion than $/ \mathrm{a} /($ estimate $=-0.60353$, $z=-10.72, p<0.0001)$ or $/ \mathrm{o} /($ estimate $=-0.55062, z=-9.78, p<0.0001)$, but no significant difference between $/ \mathrm{a} /$ and $/ \mathrm{o} /(p=0.615)$. This is consistent with previous findings that back vowels also favor retroflexion, as discovered by Ong and Stone (1998). Retroflexion is significantly less frequent after coronals than after labials (estimate $=$ $-0.24909, z=-3.467, p=0.00299$ ). There is no significant difference between any of the other pairs of contexts. There is no significant difference between labial and word-initial,

\footnotetext{
${ }^{11}$ This comparison is limited to the /a/ and /o/ contexts, since there were fewer postvocalic contexts with /i/, and /1/ was excluded.
} 
and the trend is in the opposite direction of that observed by Westbury and colleagues (1998). ${ }^{12}$ Finally, there is no significant difference between stops and fricatives ( $p=$ 0.202), although the trend is in the direction that would be expected on the basis of the idea that fricatives require more articulatory precision than stops and therefore may disfavor retroflexion.

While more subjects retroflex after $/ \mathrm{t} /$ than after $/ \mathrm{k} /$ when the following vowel is back, /t/ may discourage retroflexion when the following vowel is $/ \mathrm{i} /(n=1)$. Looking at the subjects individually in the next section will be more revealing about these differences and the interactions between factors.

3.4. ANALYSIS OF INDIVIDUAL $/ \mathbf{a} /$-ALLOPHONY PATTERNS. Figure 5 shows the rates of retroflexion in prevocalic and postvocalic contexts for all of the subjects. The two retroflex-only subjects are represented by the leftmost column, and the sixteen bunchedonly subjects are represented by the rightmost column. The nine subjects with variation between these two categories are represented by the other columns. The area of each bubble indicates the rate of retroflexion for each subject in each context. Bubbles representing less than $100 \%$ retroflexion are dark gray instead of black.

\section{Retroflexion rate by subject and context}

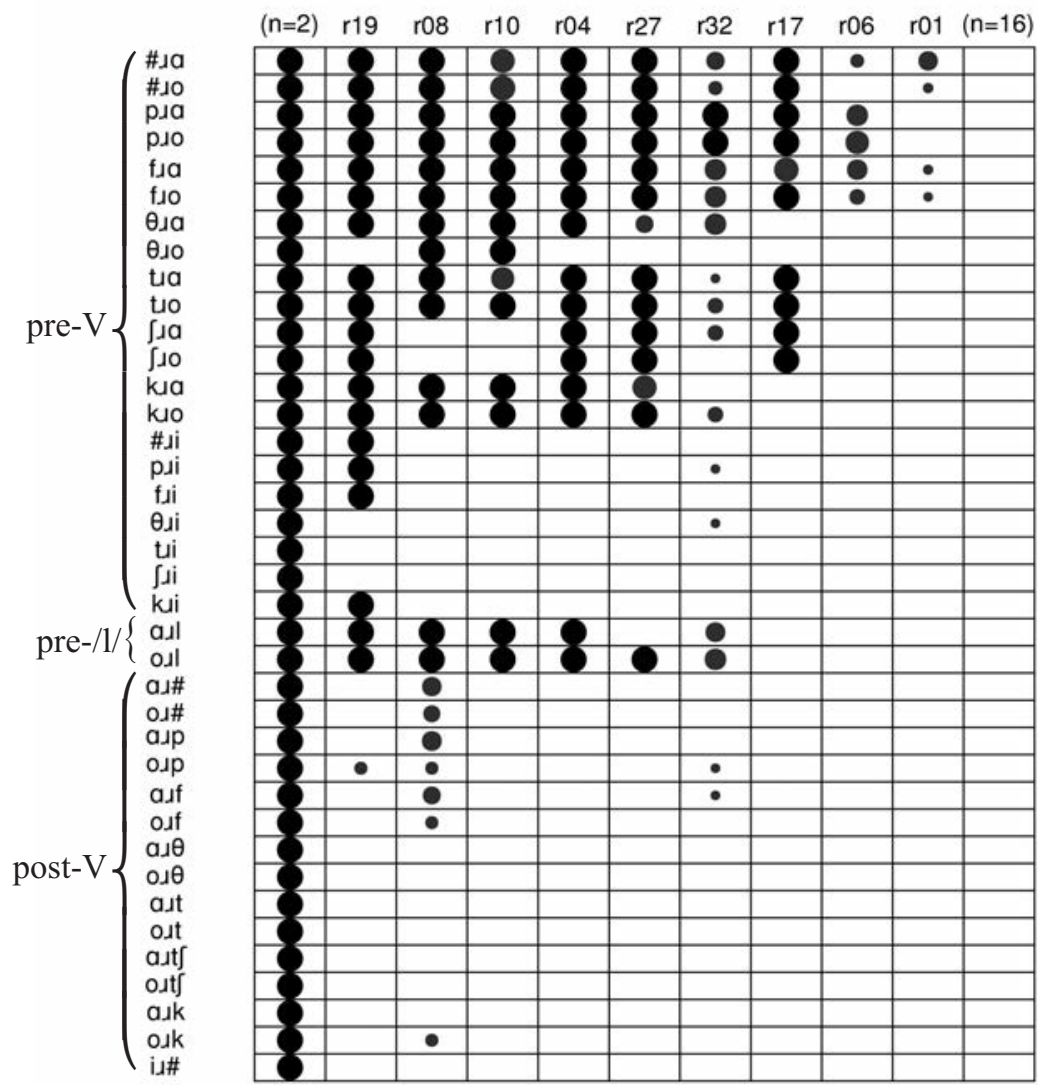

FIGURE 5. Retroflexion rates for prevocalic and postvocalic / $/ \mathrm{x}$. Here and elsewhere, circle area represents rates of retroflexion.

12 One possible explanation for lower-than-expected retroflexion rates in word-initial position is that our carrier phrase 'Please say _ again' puts the high-front offglide of [eI] before the initial segment of the target word, which would favor bunching, and a labial consonant may have the effect of distancing the $/ \mathrm{x} /$ from the 
We use OPTIMALITY THEORY (OT)-style constraints in a phonological description of each speaker's / $\mathbf{I} /$-allophony pattern. The OT framework (Prince \& Smolensky 2008) is useful for characterizing, in terms of constraints that appear to be phonetically grounded, the sometimes complex sets of environments where bunched and retroflex $/ \mathrm{x} /$ occur. We treat this as a technique for modeling speaker behavior while making reference to its apparent phonetic basis, and not necessarily as a model of how the speakers mentally represent the patterns. Using phonetically defined constraints also allows us to quantify the complexity of a speaker's / $\mathrm{x} /$-allophony pattern. For example, the nine segmentally defined prevocalic contexts where speaker r10 does not retroflex can be described with just two phonetically defined constraints, because the contexts are all either post-/S/ or pre-/i/.

Since bunching is observed most frequently in environments that seem to be the least articulatorily compatible with retroflexion, we make use of a constraint requiring retroflexion (i.e. making retroflex the default) and its interaction with constraints that prohibit retroflexion in some or all contexts. This constraint and all other constraints that are applicable to the $/ \mathbf{I} /$-allophony patterns we observed are shown in Table 3 . The two retroflex-only subjects show no evidence of any constraints other than $*_{I}\left({ }^{*}\right.$ BUNCHED). Likewise, ${ }^{*}\left({ }^{*}\right.$ Retroflex $)$ is undominated for the sixteen bunched-only subjects.

\begin{tabular}{|c|c|c|c|c|}
\hline & CONSTRAINT & ABBREVIATION & CONTEXTS & SUBJECTS \\
\hline a. & *BUNCHED & $*_{\mathrm{I}}$ & N/A & $4+$ \\
\hline b. & *RETROFLEX & $*_{t}$ & N/A & $16+$ \\
\hline c. & *RETROFLEX/CODA & *CODA & 15 & 8 \\
\hline d. & *SYLLABIC /1/ & $* 1$ & 2 & 3 \\
\hline e. & *Retroflex / _ i & $*$ li & 7 & 8 \\
\hline f. & *Retroflex / [+Lingual $]$ & $*[$ Ling $]$ ¿ & $8-12$ & 2 \\
\hline g. & $*$ Retroflex / $\theta \_o$ & $* \theta_{\text {¿̨o }}$ & 1 & 5 \\
\hline h. & *RETROFleX / $\int_{-}$ & $* \int_{t}$ & $2-3$ & 2 \\
\hline i. & *RETROFLEX / _ $[+$ +Coronal $]$ & $*_{t}[\mathrm{Cor}]$ & 6 & r19 \\
\hline $\mathrm{j}$. & *Retroflex / [+Coronal $] \_\mathrm{i}$ & *[Cor $]$ [i & 3 & r08 \\
\hline $\mathrm{k}$. & $*$ Retroflex / $\theta$ & $* \theta_{\imath}$ & $2-3$ & r17 \\
\hline 1. & *RETROFLEX / k _ & $*_{\mathrm{k}_{\downarrow}}$ & $2-3$ & r17 \\
\hline $\mathrm{m}$. & *Retroflex / i _ & *i. & 1 & r08 \\
\hline $\mathrm{n}$. & *Retroflex / p _ & *pt & $2-3$ & r01 \\
\hline o. & ${ }^{*}$ Retroflex / k_a & *k.a & 1 & r32 \\
\hline p. & *Retroflex / ${ }^{\prime}$ _o & 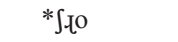 & 1 & r32 \\
\hline q. & *Retroflex / a 1 & *a $a_{1} l$ & 1 & r27 \\
\hline r. & *Retroflex / \#_o & *\#ґо & 1 & r06 \\
\hline s. & *Retroflex / $\mathrm{a} \_\mathrm{k}$ & $*_{\mathrm{a} J \mathrm{k}}$ & 1 & r08 \\
\hline
\end{tabular}

TABLE 3./r/ constraints.

The nine speakers with categorical variation require context-specific constraints. The most conspicuous set of environments prohibiting retroflex / $/$ / are postvocalic. Six speakers produce retroflex $/ \mathrm{d} /$ in some contexts but never or almost never word-finally or before consonants other than $/ 1 /,{ }^{13}$ and three of these do not produce retroflex $/ \mathrm{x} /$ before word-final /1/ either.

vowel, increasing retroflexion indirectly. However, little is known about how coarticulation affects / $\mathrm{x} /$ tongue posture across word boundaries.

13 This includes r19 and r32, who each have a small number of contexts where they show a low rate of retroflexion, but otherwise do not retroflex in postvocalic position. We are glossing over these facts at this point, because both subjects clearly disfavor retroflexion across a wide range of contexts, and we have insufficient data to conclude that there is not a more specific situation favoring retroflexion in the isolated contexts where a low rate of retroflexion occurs anyway. 
The constraint * CoDA $x$ applies to avoidance of retroflexion in coda $/ \mathrm{x} /$. The motivation for this constraint could be related to a preference for larger anterior gestures in onset position that has been observed in a wide range of consonants (Sproat \& Fujimura 1993, Browman \& Goldstein 1995, Gick et al. 2006), including English / $\mathbf{x} /$ (Delattre \& Freeman 1968, Zawadski \& Kuehn 1980, Gick 1999, Campbell et al. 2010). This preference favors retroflexion in onsets, but tip-up and tip-down tongue postures are both used successfully to achieve $/ \mathbf{A} /$ in all syllable positions.

Subjects with a preference for retroflexion in prevocalic position are split over whether /1/ patterns with consonants or with vowels. The syllable position of $/ \mathbf{x} /$ is ambiguous when it precedes $/ 1 /$, so $/ \mathbf{I} /$ variation here can be treated as variation in $/ \mathbf{I} /$ 's syllable position, as illustrated in 2 . Subjects $\mathrm{r} 13, \mathrm{r} 30$, and $\mathrm{r} 08$ retroflex in postvocalic position, as shown by $[\tau]$ in all words in 2 . Subject $\mathrm{r} 01$ and the sixteen subjects who never retroflex have bunched $[\mathrm{I}]$ in all words in 2 . The middle two groups of subjects do not generally retroflex in postvocalic position, as shown by $[\mathrm{x}]$ in $2 \mathrm{c}$. The fact that $\mathrm{r} 19$, $\mathrm{r} 10, \mathrm{r} 04$, and $\mathrm{r} 32$ retroflex before $/ 1 /$ but not $/ \mathrm{p} /$ is accounted for if they treat $/ \mathrm{x} /$ in Carl, gnarl, and snarl as an onset, while $\mathrm{r} 27, \mathrm{r} 17$, and r06 treat it as a coda, like $/ \mathrm{x} /$ before $/ \mathrm{p} /{ }^{14} \mathrm{We}$ do not have direct evidence of the subjects' intuitions of the syllabicity of $/ 1 /$, but it is the only word-final $/ \mathrm{x} /$-adjacent segment whose syllabicity is ambiguous, and the only segment associated with such categorical variation. We can posit that *1 outranks *CODA $\downarrow$ for the speakers who do not retroflex before word-final $/ 1 /$.

(2) Apparent effect of /1/ syllabicity on retroflexion.

r13, r30, r08 r19, r10, r04, r32 r27, r17, r06 r01 and 16 others

\begin{tabular}{|c|c|c|c|c|}
\hline a. pцар & p.tap & рџар & pıap & 'prop' \\
\hline p.lam & p.am & p. & pram & 'prom' \\
\hline pran & pıan & płan & pran & 'prawn' \\
\hline b. karl & ka.._1 & kaul & kasl & 'Carl' \\
\hline nasl & na.. 1 & nasl & nasl & 'gnarl' \\
\hline snasl & sna.t. 1 & snasl & snasl & 'snarl' \\
\hline c. hasp & hasp & hasp & hasp & 'harp' \\
\hline $\int a_{\mu p}$ & Sasp & Saxp & Sasp & 'sharp' \\
\hline ka.p & kasp & kasp & kasp & 'carp' \\
\hline
\end{tabular}

Figure 5 above shows thirty-eight phonological contexts (rows), meaning there are 342 cells representing a context where one of the nine speakers with categorical variation could produce at least some retroflexion. No retroflexion is observed in 222 of these cells, and another five are cells with low retroflexion rates scattered among cells with no retroflexion, for speakers who exhibit much higher rates of retroflexion in other contexts, leading us to group them with the contexts with no retroflexion. Syllable position alone (i.e. *CoDA $t$ ) accounts for 123 cells, or $55.4 \%$ of all instances where no retroflexion is observed for speakers who sometimes bunch and sometimes retroflex. The other relevant constraints on retroflexion refer to classes of segments. ${ }^{15}$

\footnotetext{
${ }^{14}$ Note that speakers shown in the rightmost column could have either syllabification of $/ 1 /$ because they bunch both in onsets and in codas. Also note that subject r27 treats /aul/ and /oul/ differently.

${ }^{15}$ While we recognize that not all phonologically active classes of sounds are phonetically natural (Mielke 2008), we expect effects with direct phonetic motivation to involve phonetically coherent contexts. Since the $/ \mathrm{x} /$-allophony patterns discussed here each appear to be motivated by phonetic factors internal to the speaker, we do not expect them to exhibit the effects of rule telescoping or the like that might give rise to phonetically unnatural classes involved in other sound patterns.
} 
Eight of the thirteen speakers who produce retroflex $/ \mathrm{x} /$ in some contexts never do so before $/ \mathrm{i} /$, and thus ${ }^{*} \mathrm{i}$ is the most frequent constraint that refers to segments. Stavness and colleagues (2012) used biomechanical modeling to explore the articulatory basis for the association of bunching with /i/ and retroflexion with /a/. In the context of $/ \mathrm{i} /$, bunched $/ \mathbf{x} /($ relative to tip-up $/ \mathbf{x} /$ ) showed a reduction in all three articulatory cost measures they considered (tissue displacement, relative strain, and relative muscle stress). Likewise, retroflex $/ \mathbf{x} /$ showed a reduction in all three measures in the context of $/ \mathbf{a} /$.

The first two context-sensitive constraints account for nearly $80 \%$ of all contested cells, leaving forty-five cells where other constraints are necessary. Of these, sixteen are accounted for by a constraint prohibiting retroflexion after lingual consonants (*[Ling $]_{\mathrm{t}}$ ). The phonetic basis for this constraint is that consonants requiring the tongue to be in a particular location favor bunching more than retroflexion. The two subjects it applies to (r06 and r01) retroflex only between labial consonants and back vowels. Other subjects produce retroflex $/ \mathrm{x} /$ in some contexts next to lingual consonants and not in others.

Four speakers have bunching in $/ \theta_{\mathrm{\lrcorner o}} /$ and retroflexion in $/ \theta_{\mathrm{\jmath a}} /$, motivating $* \theta_{\text {๘o }}$, the most specific of the recurrent constraints. Figure 6 illustrates a motivation for this by showing r04's tip-up / $\theta \mathrm{ua} /$ and tip-down $/ \theta \mathrm{xo} /$ in two series of tongue traces spaced 67 $\mathrm{ms}$ apart. The $/ \mathrm{x} /$ frame is indicated by a thicker trace, the traces corresponding to different segments are indicated by phonetic symbols at the tongue tip (on the right), and a dotted arrow indicates the movement from the first frame to the last in each sequence. ${ }^{16}$ In Fig. 6a, the tongue body stays in roughly the same position throughout the sequence $/ \theta \mathrm{sa} /$, and $/ \mathrm{x} /$ is achieved by raising the tongue tip. In Fig. $6 \mathrm{~b}$, the tongue body moves back from $[\theta]$ to $[0]$, and the tongue blade is raised only slightly to achieve $/ \mathrm{I} /$. When r04's tongue moves from $[\theta]$ to [o], it passes through a configuration that is similar to r04's bunched $/ \mathrm{x} /$. This does not happen with the lower $[\mathrm{a}]$, and the tongue tip is retroflexed in order to achieve the acoustic target for $/ \mathrm{x} / \mathrm{.} / \mathrm{x} /$ may also be flapped after $/ \theta /$ in English, and this audible difference may also impact $/ \mathbf{x} /$ articulation in this context.

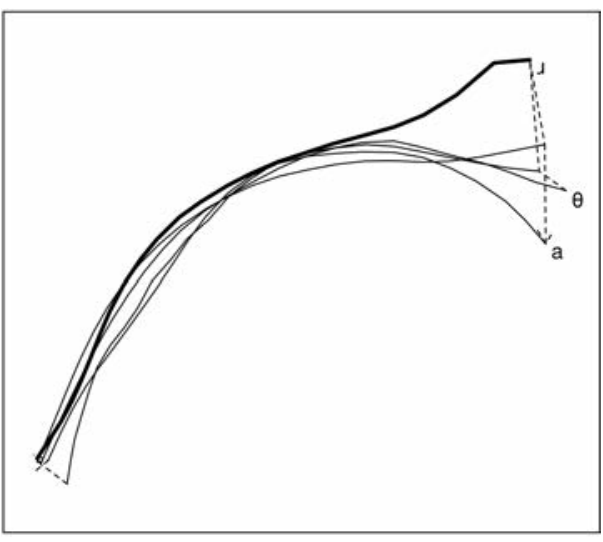

a. Tip-up / $/ \mathrm{d}$ in throng.

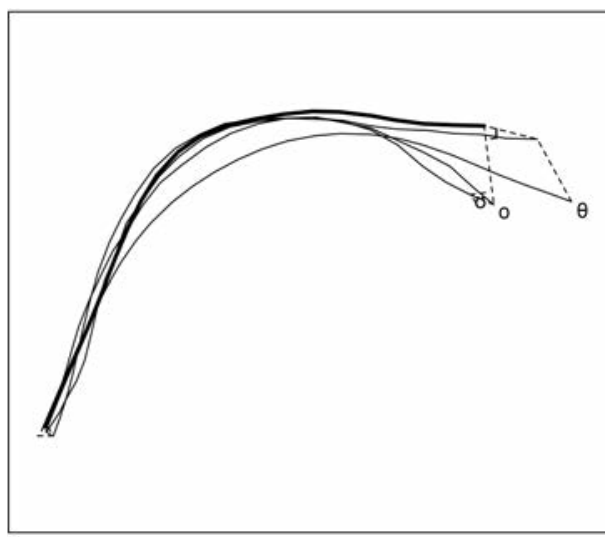

b. Tip-down $/ \mathrm{x} /$ in throw.

FIGURE 6. Subject r04.

\footnotetext{
${ }^{16}$ These and all subsequent traces are made by including every other video frame (i.e. frames in the figures are $67 \mathrm{~ms}$ apart), because traces from adjacent frames would be too close together to be interpretable in the figure. See n. 9 above for details about the relationship between scanning rate and video frame rate.
} 
The only other constraint that is applicable to more than one subject involves $/ \int \mathrm{x} / . / \mathrm{S} /$ is typically articulated with a tongue posture similar to bunched $/ \mathrm{x} /$, and it involves tongue-blade raising less frequently than $/ \mathrm{t} /$ and $/ \theta /$. Figure 7 shows a series of frames from r08's shriek, motivating the constraint ${ }^{*} \tau$ ( (and also * ${ }^{2}$ i). The tongue dorsum is raised for all of the segments in the word, including the [S], the [i], and the bunched variant of $/ \mathbf{x} /$ that occurs between them.

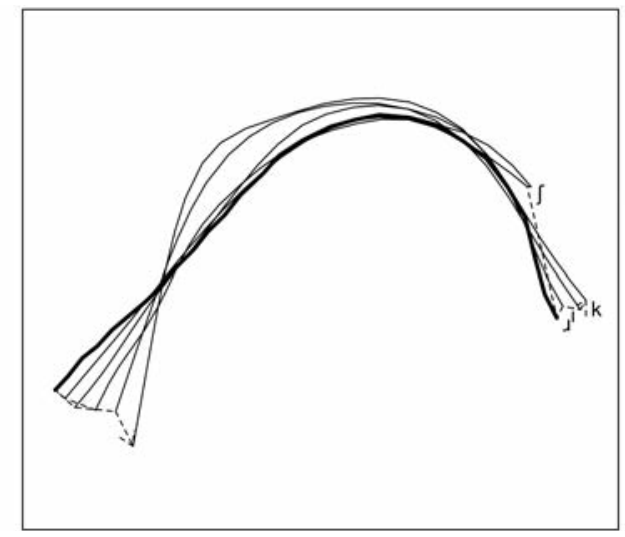

FIGURE 7. Phonetic motivation for * $\{i$ and $*[$ Cor $]$ цi: r08 shriek (tip-down /x/).

r19 bunches between a coronal consonant and /i/, and this is accounted for by *[Cor] [i. r08 bunches before coronal consonants (but retroflexes in most other preconsonantal contexts), and this is accounted for by ${ }^{*}[$ Cor $]$. The constraints in Table $3 \mathrm{k}-\mathrm{m}$ above involve particular consonants that seem to supply a phonetic motivation for the absence of retroflexion, but they are observed in only one subject each. *i., obeyed by one subject, does not seem to be any less phonetically motivated than its mirror-image constraint, exhibited by eight, but it is infrequent because a small number of subjects bunch in any postvocalic context. Further, /ix\#/ is the only postvocalic context involving /i/, because consonant clusters involving / $/ \mathbf{s}$ are rare after $/ \mathbf{i} /$ in English. Walker and Proctor (2013) attribute the rarity of these clusters to the gestural incompatibility of $/ \mathrm{i} /$ and $/ \mathrm{x} /$, which prevents the temporal overlap that is typical in sequences of $/ \mathrm{a} o / \mathrm{o} / \mathrm{x} /$.

The way in which the constraints account for bunching contexts is shown in Figure 8. Each constraint is indicated by a shaded rectangle covering the contexts and subjects where retroflex $/ \mathbf{x} /$ is prohibited. Rectangles for some constraints (such as $* \theta_{\text {孔o }}$ ) are discontinuous because they apply to subjects who are not contiguous in the chart. The remaining cells without retroflexion are indicated by '...' in Fig. 8. The constraints covering these cells are purely stipulative (Table $3 \mathrm{~m}-\mathrm{s}$ ), except for $*_{\mathrm{i}_{\chi}}$ (the mirror image of * $(\dot{i})$. The others have no apparent phonetic motivation, and most are only applicable to one context for one subject.

The use of independent constraints for different contexts suggests that a speaker's $/ \mathrm{x} /$-allophony grammar could make use of any combination of them. This is known as factorial typology in the OT literature (Prince \& Smolensky 2008, et seq.). However, some contexts appear to be less favorable to retroflexion than others. For example, no subject exhibits a consonant-sensitive constraint without also exhibiting *CoDA $\_$or * $\{$i. Subjects r06 and r01 have the lowest nonzero retroflexion rates, and they retroflex in environments where all of the other subjects with any retroflexion also produce the retroflex allophone. Some of the constraints could be placed in an implicational hierarchy according to the apparent strength of their phonetic motivations: without exception, 
Retroflexion rate by subject and context

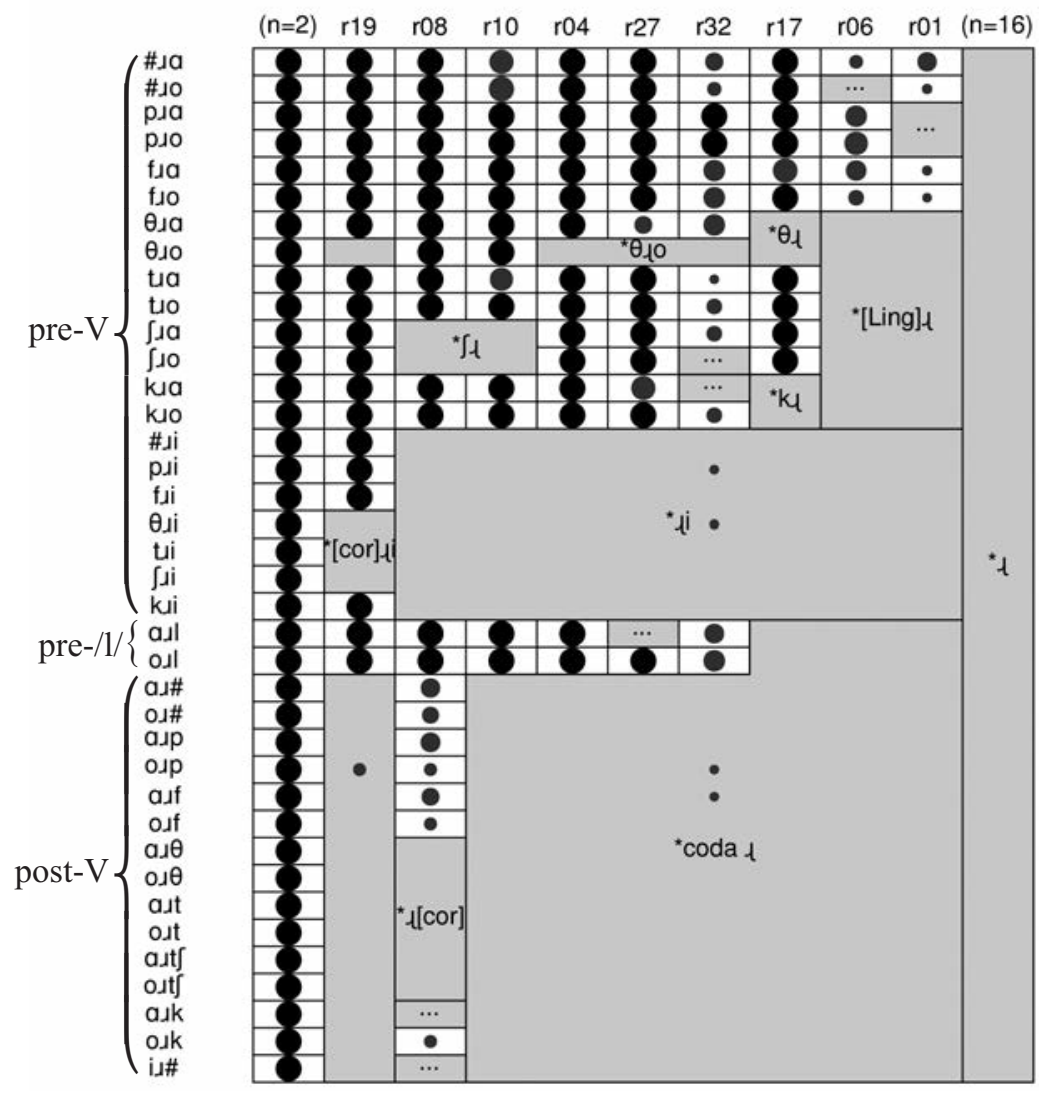

FIGURE 8. Context-specific constraints.

retroflexion in a postvocalic context implies retroflexion in the corresponding prevocalic context, and except for the special case of $/ \theta \mathrm{Jo} /$, retroflexion in any context next to /i/ implies retroflexion in the corresponding context next to /a o/.

Some phonetic motivations are speaker-specific. $\mathrm{r} 08$ and $\mathrm{r} 10$ retroflex after $/ \mathrm{k} / \mathrm{but}$ not $/ \mathrm{S} /$, while $\mathrm{r} 17$ retroflexes after $/ \mathrm{s} /$ but not $/ \mathrm{k} /$. Figure 9 shows $\mathrm{r} 08$ and $\mathrm{r} 17$ producing the words Shrop and crop. Both speakers appear to be making the tongue posture that is most compatible with the surrounding segments, and the difference between the two is attributable to the fact that the context for $/ \mathrm{a} /$ involves a tip-down $/ \mathrm{J} /$ for $\mathrm{r} 08$ (and r10) and a tip-up $/ \mathrm{S} /$ for $\mathrm{r} 17$. For $/ \mathrm{kJa} /$, the subjects have the opposite pattern. r08's retroflex tongue posture involves a more raised tongue body, an articulation that is more compatible with an adjacent velar stop.

We have seen in this section that many of the same constraints are applicable to the $/ \mathrm{x} /$-allophony patterns of different speakers. The most frequently needed constraints have straightforward phonetic motivations, and the major differences between allophony patterns can be described as presence or absence of particular phonetically motivated constraints against retroflex $/ \mathbf{x} /$ in particular contexts. The most natural contexts for retroflex $/ \mathrm{s} / \mathrm{are} / \mathrm{H}_{\mathrm{sa}} / \mathrm{g} / \mathrm{p} \mathrm{sa} /$, and other prevocalic contexts without lingual consonants, and the most natural contexts for bunched $/ \mathrm{x} /$ are $/ \int \mathrm{si} /$ and other postcoronal pre/i/ contexts, along with most postvocalic contexts. An American English speaker who retroflexes in shriek is likely to retroflex in most if not all contexts, and a speaker who 


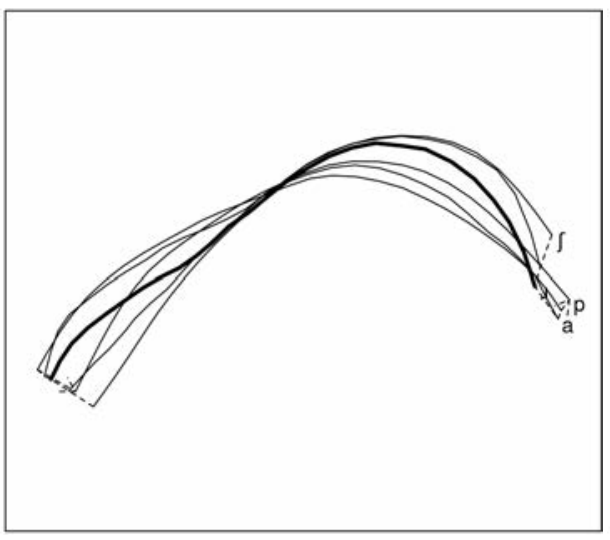

a. r08 Shrop (tip-down/x/).

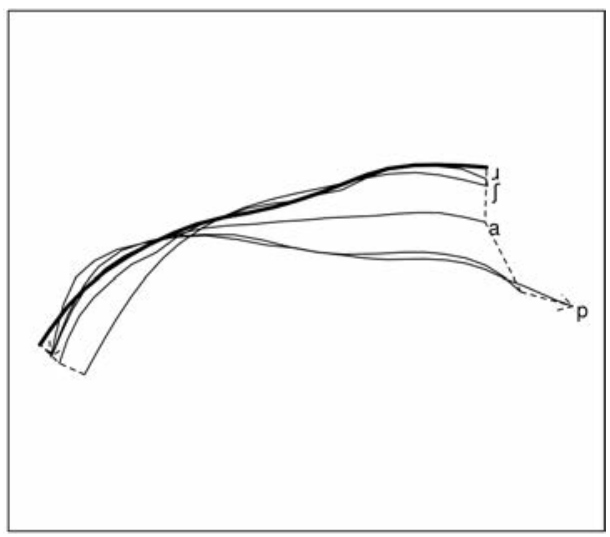

c. r17 Shrop (tip-up/s/).

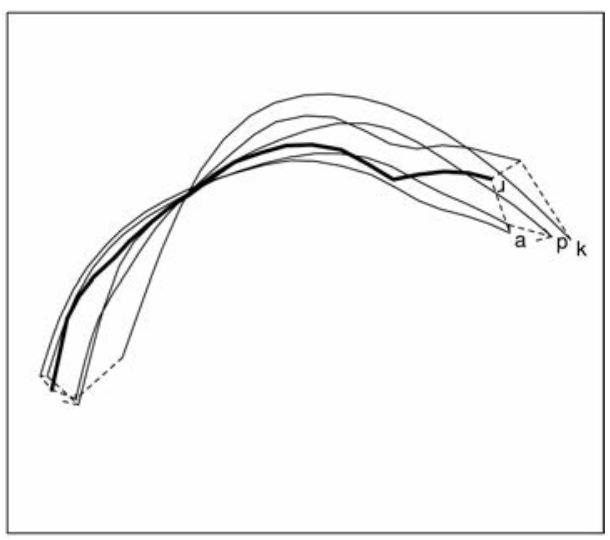

b. $\mathrm{r} 08 \operatorname{crop}(\operatorname{tip}-u p / \mathrm{x} /)$.

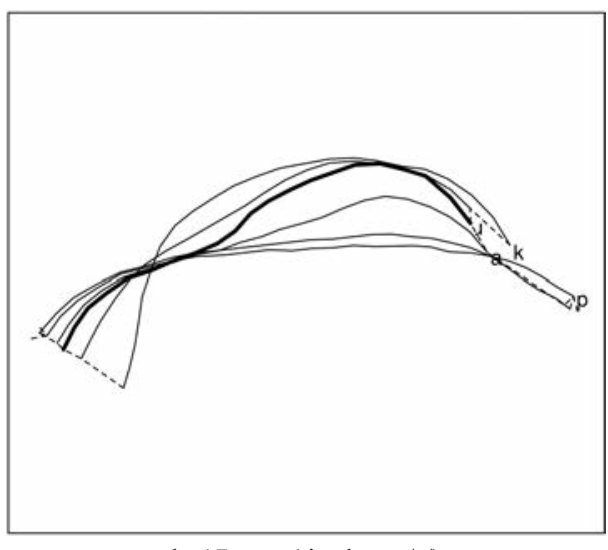

d. r17 crop (tip-down/s/).

FIGURE 9. Speaker-specific motivation: r08: tip-down / / / for Shrop (a) vs. tip-up / / / for crop (b); r17: tip-up $/ \mathrm{d} /$ for Shrop (c) vs. tip-down /. $/$ for $\operatorname{crop}(\mathrm{d})$.

bunches in rock is likely to bunch everywhere. Since we are primarily concerned with categorical tip-up/tip-down allophony, we do not report on gradient variation within the productions of the sixteen speakers with only bunched $/ \mathrm{I} /$ or the two with only retroflex $/ \mathrm{x} /$. A more detailed investigation would likely show a pattern similar to the one Westbury and colleagues (1998) observed, that is, that bunched tongue shapes are more extreme in many of the contexts that retroflex $/ \mathrm{x} /$ is found in, with relatively restrictive segmental contexts reining in extreme variants of both kinds of $/ \mathrm{x} /$.

The most important reason for the individual patterns of $/ \mathrm{x} / \mathrm{allophony} \mathrm{seems} \mathrm{to} \mathrm{be}$ that language users do not perceive the difference between allophones, and so establishing a community-wide allophony pattern is impossible. We can imagine that if the difference between bunched and retroflex / $\mathrm{a} /$ were perceptible, a community-wide allophony pattern would have emerged. This would be similar to the actual situation with /1/ allophony in English, where postvocalic /1/ is typically darker than prevocalic /1/. In the next section we investigate crosslinguistic variation in /1/ allophony, which resembles intraspeaker variation in $/ \mathbf{x} /$ allophony we have seen so far.

4. /1/ ALLOPHONY. In this section we survey allophonic patterns involving clear and dark $/ 1 /$, in order to put $/ \mathbf{I} /$ allophony in the context of other liquid allophony patterns. 
The most obvious difference between American English / $\mathrm{I} /$ allophony and the reported cases of /1/ allophony is that while /1/ allophones are noticeably different from one another, $/ \mathrm{I} /$ allophones are not. We investigate some of the consequences of this difference. The generally accepted pattern of /1/ allophony in English is that postvocalic /1/ is 'dark' [ 1 , that is, more vowel-like than the 'clear' or 'light' [1] that occurs in prevocalic position. The [1] and [1] differ in the magnitude and timing of the coronal and dorsal gestures (Sproat \& Fujimura 1993, Alwan et al. 1997). The clear-dark pattern is particularly apparent in Southern British English. In other varieties, such as American and Scottish English, it can be argued that /1/ is always dark, although postvocalic /1/ is still darker than prevocalic $/ 1$, and intermediate degrees of darkness can be observed in intervocalic position.

The English syllable-based pattern is reminiscent of $/ \mathrm{x} /$ allophony, where prevocalic $/ \mathrm{x} /$ is more likely to be retroflex, while both postvocalic and syllabic $/ \mathrm{x} / \mathrm{s}$ are more likely to be bunched. It also seems reasonable for /1/ darkening to be sensitive to segmental factors, since it involves a tongue-body gesture that is found in some consonants and vowels. Recasens and Espinosa (2005) report that even in languages without reported allophony patterns, $/ 1 /$ and $/ \mathfrak{t} /$ are generally darker next to $/ \mathrm{u} /$ and word-finally than next to /i/ and word-initially.

It is important to bear in mind that the level of description for the /1/-allophony patterns surveyed is different from the / $\mathrm{x} /$-allophony patterns seen above. More detailed instrumental study of any of the languages involved in the survey would certainly show more gradient effects and speaker-specificity than is apparent from a high-level phonological description. For example, Sproat and Fujimura's (1993) x-ray microbeam study of American and British English /1/ showed interspeaker differences, and showed that the allophony pattern in general is arguably gradient. However, the observed differences between allophones of $/ 1 /$ are related to the effects of syllable position, realized somewhat differently across contexts and subjects. By contrast, it would not make sense to talk about American English / $\mathrm{x} /$ allophony without referring to a range of factors related to syllable position and segmental context. Different speakers of American English show categorically different sets of conditioning factors for $/ \mathrm{A} /$ allophony, but the /1/-allophony patterns surveyed in the next section exhibit these types of differences on a language-by-language basis.

4.1. SuRvey and anAlysis of /1/-ALlOPHONY PATterns. Many languages, such as French and Italian, have a relatively light [1] in all contexts, and some are like American and Scottish English in having a relatively dark [1] in all contexts. ${ }^{17}$ Others languages such as Russian have a phonemic contrast between clear and dark lateral liquids. A number of languages have an allophonic pattern where /1/ is light in some contexts and dark in others. As with the American English/ $\mathrm{x} /$-allophony patterns described above, there are recurrent contexts where the two types of allophones are frequently observed. ${ }^{18}$

The allophony pattern described for British English (Catford 1988:109) is also described for Dutch (Booij 1999:8), Brazilian Portuguese (Feldman 1972), Mundari (Cook 1974), and Taos (Trager 1948). A rule-based description of this pattern is given in 3.

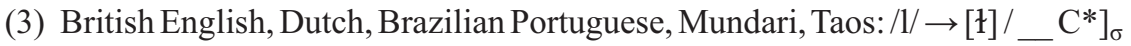

\footnotetext{
${ }^{17}$ See Archangeli et al. 2010 for an ultrasound study of the light French /1/.

${ }^{18}$ This survey is based on a search of P-base (Mielke 2008, Brohan \& Mielke 2016) (http://phon.chass.ncsu .edu/pbase-app/) and following up references on the Wikipedia page 'Velarized alveolar lateral approximant' (http://en.wikipedia.org/wiki/Velarized_alveolar_lateral_approximant).
} 
This pattern and the other /1/-allophony patterns are summarized in Figure 10. As above with $/ \mathbf{x} /$, the contexts where dark $[1]$ is observed (cells with no circle) can be accounted for with phonetically motivated constraints against the other allophone. The default allophones are established with the constraint * ${ }^{*}$, which is motivated in languages with only [1] and in languages with [1] in contexts where [1] does not occur, and the constraint *1, which is motivated in Scottish and American English and other languages where $/ 1 /$ is generally dark. These and the context-sensitive constraints are listed in Table 4 . The syllable-based pattern in 3 is handled by ranking *CoDA 1 over * $*$, and it is analogous to an unobserved $/ \mathbf{I} /$-allophony pattern in which retroflex $/ \mathbf{x} /$ occurs in onsets and bunched $/ \mathbf{x} /$ occurs in codas.

\section{Clear /// by language and context}

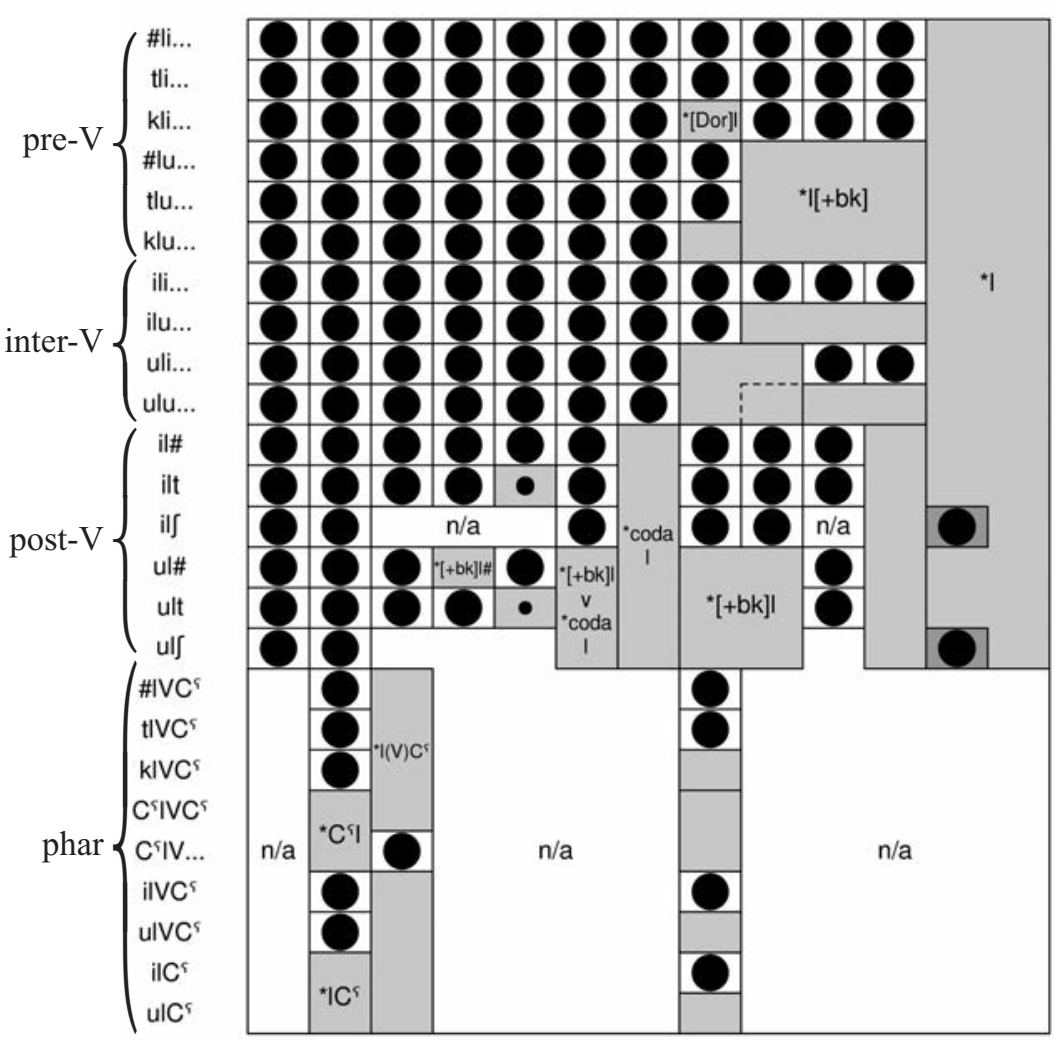

FIGURE 10. Contexts for clear /1/ across languages: Fr: French, Italian; AN: Assyrian Neo-Aramaic (Jilu dialect); AA: Abha Arabic; Kh: Kharia; Al: Alabama; No: Norwegian (some dialects); BE: British English, Dutch, Brazilian Portuguese, Mundari, and Taos; JA: Jordanian Arabic; Tu: Turkish and Kirghiz; Fi: Boumaa Fijian; Ge: Georgian; Bu: Buriat; SE: Scottish English, American English. Gray areas with ' $\mathrm{n} / \mathrm{a}$ ' indicate nonoccurring contexts. ' $k$ ' indicates a velar consonant, ' $\int$ ' represents $/ \int 3 /$, preceding ' $t$ ' indicates a nonvelar consonant, following ' $\mathrm{t}$ ' indicates a non- $/ \int 3 /$ consonant, and ' ...' indicates anything that is not a pharyngealized consonant. Context-specific constraints are introduced below.

Another recurrent /1/-allophony pattern is sensitive to vowel quality. In Boumaa Fijian (Dixon 1988), /1/ is dark before a back vowel (which also involves a dorsal raising gesture similar to velarization), as in 4. Kirghiz (Poppe \& Hebert 1963) and Turkish 


\begin{tabular}{|c|c|c|c|}
\hline & CONSTRAINT & ABBREVIATION & LANGUAGES \\
\hline a. & *DARK & $* 1$ & $17+$ \\
\hline b. & *Clear & $* 1$ & $3+$ \\
\hline c. & *CLEAR/CoDA & *CoDA 1 & 6 \\
\hline d. & *CLEAR / $-\left[\begin{array}{l}+ \text { syllabic } \\
+ \text { back }\end{array}\right]$ & $* 1[+\mathrm{bk}]$ & 5 \\
\hline e. & $*$ CLEAR / $\left[\begin{array}{l}+ \text { syllabic } \\
+ \text { back }\end{array}\right]-$ & $*[+\mathrm{bk}] 1$ & 4 \\
\hline f. & *CLEAR / $\left[\begin{array}{l}+ \text { syllabic } \\
+ \text { back }\end{array}\right]$ — $]_{\text {word }}$ & $*[+\mathrm{bk}] \mathrm{l} \#$ & Kharia \\
\hline g. & *CLEAR / _ [+ consonantal $]$ & $* 1 \mathrm{C}$ & Alabama \\
\hline h. & $*^{*}$ LEEAR $/\left[\begin{array}{c}+ \text { syl } \\
+ \text { back }\end{array}\right]-[+$ cons $]$ & $*[+\mathrm{bk}] 1 \mathrm{C}$ & Alabama \\
\hline i. & $*$ CLEAR / $\left[\begin{array}{c}+ \text { cons } \\
+ \text { low }\end{array}\right]-$ & $* \mathrm{C}^{\mathrm{s}} 1$ & 2 \\
\hline j. & *CLEAR / $-\left[\begin{array}{l}+ \text { cons } \\
+ \text { low }\end{array}\right]$ & $* 1 \mathrm{C}^{\mathrm{\varsigma}}$ & A. Neo-Aramaic \\
\hline $\mathrm{k}$. & ${ }^{*}$ CLEAR / _ $([+$ syl $])\left[\begin{array}{c}+ \text { cons } \\
+ \text { low }\end{array}\right]$ & $* 1(\mathrm{~V}) \mathrm{C}^{\mathrm{\varsigma}}$ & Abha Arabic \\
\hline 1. & *CLEAR / [+Dorsal $]$ & $*[$ Dor $] 1$ & Jord. Arabic \\
\hline $\mathrm{m}$. & *DARK / _ $\left[\begin{array}{l}+ \text { sibilant } \\
\text {-anterio }\end{array}\right]$ & *1s & Buriat \\
\hline
\end{tabular}

TABLE 4. /1/ constraints.

(Lewis 1967) exhibit a similar pattern, where /1/ is dark before AND after a back vowel, as in 5 .

(4) Boumaa Fijian: $/ 1 / \rightarrow[1] /\left[\begin{array}{l}+ \text { syllabic } \\ + \text { back }\end{array}\right]$

(5) Kirghiz and Turkish: $/ \mathrm{l} / \rightarrow[\mathrm{t}] /\left[\begin{array}{l}+ \text { syllabic } \\ + \text { back }\end{array}\right] \ldots ;-\left[\begin{array}{l}\text { +syllabic } \\ + \text { back }\end{array}\right]$

The Boumaa Fijian pattern can be described using the constraint * $1[+\mathrm{bk}]$ ranked above $* \nmid$. This is analogous to the constraint * $\{\mathrm{i}$ above in 3 , which prohibits retroflex $/ \mathbf{x} /$ before /i/. *l[+bk] and its mirror-image constraint *[+bk]l account for Kirghiz and Turkish. A similar pattern is observed in some dialects of Norwegian (Kristoffersen 2007), where $/ 1 /$ is dark after a tautosyllabic back vowel, ${ }^{19}$ as in 6 . This can be described by the conjunction of *[+bk]l and *CODA 1 .

(6) Norwegian (some dialects): $/ 1 / \rightarrow[1] /\left[\begin{array}{c}+ \text { syllabic } \\ + \text { back }\end{array}\right]$ _ (when tautosyllabic)

Two other languages have allophony patterns related to preceding back vowels. In Kharia (Bilgiri 1965), word-final /1/ is dark after a back vowel, as in 7 . This combines a domain-final pattern like the one in 3 with the back-vowel pattern observed in the other languages discussed so far, and it is handled by $*[+\mathrm{bk}] 1$ \#. This could be treated as constraint conjunction as well, but we do not see evidence for a constraint that refers to word-final position but not to back vowels. Another/1/-allophony pattern is found in Alabama (Lupardus 1982), where /1/ is optionally dark before a consonant, especially when it is also preceded by a back vowel (8). This is handled by the constraints *1C and $*[+\mathrm{bk}] \mathrm{lC}$.

(7) Kharia: $\left./ 1 / \rightarrow[1] /\left[\begin{array}{l}+ \text { syllabic } \\ + \text { back }\end{array}\right] \_\right]_{\text {word }}$

(8) Alabama: $/ 1 / \sim[1] / \ldots C$, especially $\left[\begin{array}{c}+ \text { syllabic } \\ + \text { back }\end{array}\right]$ C

Another group of /1/-allophony patterns are sensitive to specific types of consonants. In the Jilu dialect of Assyrian Neo-Aramaic (Odisho 1988), /1/ is dark when it is adja-

\footnotetext{
${ }^{19}$ When $/ 1 /$ is followed by a stressed vowel it is an onset, and the light allophone occurs regardless of what vowel precedes.
} 
cent to a pharyngealized consonant, as in 9 . This presents a consonant that is compatible with [1] (or incompatible with clear [1]), in addition to the syllable position and vowel contexts already seen. This pattern is covered by the constraints ${ }^{*} \mathrm{C}^{\S} 1$ and ${ }^{*} 1 \mathrm{C}^{\text {s }}$. These are analogous to the constraints on $/ \mathrm{x} /$ that prohibit the retroflex allophone next to various lingual consonants. A similar pattern is found in Abha Arabic (Nakshabandi 1988), where /1/ and some other coronal consonants are dark before a pharyngealized consonant, including across an intervening vowel, as in 10 , covered by $* 1(\mathrm{~V}) \mathrm{C}^{\text {ई }}$. The Jordanian Arabic (Al-Sughayer 1990) pattern combines a few of these patterns, as in 11. $/ 1 /$ is dark after a pharyngealized or velar consonant, with an intervening [a] possible, and after a back vowel. ${ }^{20}$ This is handled by $*[+\mathrm{bk}] 1,{ }^{*} \mathrm{C}^{\mathrm{s}} 1$, and also $*[$ Dor $] 1$.

(9) Assyrian Neo-Aramaic (Jilu dialect): /l: $/ \rightarrow[1:] / \mathrm{C}^{\mathrm{f}} \_;-\mathrm{C}^{\mathrm{s}}$

(10) Abha Arabic: /t d s ठ l/ $\rightarrow$ velarized / _ (V)C $\mathrm{C}^{\text {凡 }}$

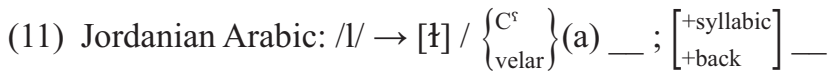

Two more allophony patterns are more succinctly described using rules deriving clear [1] from a phoneme whose default realization is dark. In Buriat (Poppe 1960), / 1 / is clear before $/ \mathrm{J} /$ and $/ 3 /$ and dark elsewhere, as in 12. In Georgian (Tschenkeli 1958), / $1 /$ is clear before a front vowel and otherwise dark, as in 13. Archangeli and Berry (2010) confirm the description of Georgian in Tschenkeli 1958 using ultrasound imaging.

(12) Buriat: $/ \mathbf{t} / \rightarrow[1] /\left[\begin{array}{l}+ \text { continuant } \\ \text {-anterior }\end{array}\right]$

(13) Georgian: / $/ 1 \rightarrow[1] /\left[\begin{array}{l}\text { +syllabic } \\ \text {-back }\end{array}\right]$

Buriat has $[1]$ in all contexts except before a postalveolar fricative. Since there is a phonetically coherent set of environments where the clear allophone occurs, and the dark allophone occurs elsewhere, this is handled with a constraint prohibiting [ł] in this context, * $*$, rather than with a patchwork of context-specific constraints against [1]. Georgian also has dark [1] in a wider range of contexts than clear [1], but the contexts where dark [1] occurs can be easily described using the same constraints used for other languages that have [1] in a phonetically coherent subset of the environments where Georgian has it.

We have seen so far that lateral liquids are often allophonically dark in postvocalic position (and word-final and preconsonantal position), which is parallel to the prevalence of bunched $/ \mathbf{x} /$ in postvocalic position in American and British English. Dark allophones also occur next to back vowels, just as bunched allophones of $/ \mathrm{J} /$ are more frequent next to $/ \mathrm{i} /$ and other front vowels. Dark allophones also occur next to pharyngealized and velar consonants, just as bunched $/ \mathbf{x} /$ often occurs next to lingual consonants. Some implicational relationships are apparent. Clear [1] in postvocalic position implies clear [1] in prevocalic position, clear [1] in the context of a back vowel implies clear [1] in the context of a front vowel, and clear [1] next to a pharyngeal implies clear [1] in the absence of a pharyngeal. The way that similar constraints are used to model [1] allophony in different languages is parallel to the way that similar constraints are used to model $/ \mathbf{x} /$ allophony in different speakers of American English. The next section discusses the important similarities and differences between language-level and subject-level variation and considers the implications for a general understanding of phonological patterns.

\footnotetext{
${ }^{20}[\mathrm{a}]$ is the allophone of the low vowel that occurs after a pharyngealized consonant, and it is not directly triggering the velarization.
} 
5. General Discussion. Like many phonological patterns, the various cases of $/ \mathbf{x} /$ and /1/ allophony reflect phonetic motivations for particular phones to appear in particular contexts. The fact that there are many patterns instead of one reflects the fact that the phonetic motivations are complex, and the path from phonetic motivations to a phonological pattern is not deterministic. Let us consider velar palatalization as a prototypical phonetically motivated sound pattern. Velar consonants typically have a more anterior point of articulation in the context of a front vowel, and the phonetic motivation is clear: vowels and dorsal consonants both involve the tongue body, and front vowels require the tongue body to be farther front than for an ordinary velar consonant. This pressure has been conventionalized in different languages. English and French both exhibit this pattern, but the degree of influence is greater in French (Ladefoged 1972, 1984). Recent ultrasound work has shown that the English pattern is gradient (Wodzinski \& Frisch 2006). Velar palatalization has reached the stage of $/ \mathrm{k} / \rightarrow\left[\mathrm{t} \int\right]$ as an allophonic pattern in languages including Gã (Zimmermann 1858), Lealao Chinantec (Rupp 1989), and Mohawk (Michelson 1983), and as a structure-preserving / $\mathrm{k} / \rightarrow\left[\mathrm{t} \int\right]$ pattern in languages including Ciyao (Ngunga 2000), Slovak (Rubach 1993), and Slovene (Herrity 2000). ${ }^{21}$ There seems to be a possible progression from phonetically motivated palatalization to conventionalized palatalization, and then to a categorical phonological pattern. ${ }^{22}$

$/ \mathrm{k} /$ palatalization is phonetically motivated in a particular environment, but /1/ darkening is phonetically motivated in multiple environments, including syllable-finally, next to back vowels, and next to pharyngealized and velar consonants. To the extent that $/ 1 /$ occurs in any of these contexts in a given language, there is a possibility for the development of a phonological darkening pattern in one or more of them. As we have seen, observed /1/-darkening patterns typically involve only one or two of the possible contexts, and the patterns are shared across community members. Thus, one thing that may distinguish / $/$ darkening from an idealized phonetically motivated sound pattern is that languages draw from one or more of several contexts where phonetic motivation is present, and the result is crosslinguistic variation between languages with patterns described as /1/ allophony.

$/ \mathrm{I} /$ allophony takes an additional step away from the idealized sound pattern. Like /1/ allophony, $/ \mathrm{x} /$ allophony exhibits multiple contexts where one of its allophones is favored, but the difference between $/ \mathrm{d} /$ allophones is not easily perceived. As a result, the consequence of having multiple phonetic motivations is that individual SPEAKERS, rather than individual LANGUAGES (or language varieties), exhibit different allophony patterns. The lack of auditory feedback reflecting tongue posture means that speakers can have different, often complex, allophony patterns. Thus, one of the factors that is involved in the development of idealized sound patterns is that speakers Do have feedback about the contexts where other speakers produce sounds with particular articulatory properties.

While we present variability of conditioning environment and speaker-specificity as properties that make $/ 1 /$ and $/ \mathbf{x} /$ allophony stand apart from the idealized, phonetically motivated sound pattern, we do not have reason to suspect that these types of patterns are in any way atypical. One of the reasons why $/ \mathbf{x} /$ allophony seems peculiar is that covert patterns cannot be studied easily without articulatory imaging. Our intuitions

${ }^{21} \mathrm{The} / \mathrm{k} / \rightarrow[\mathrm{t} \mathrm{f}]$ count is based on a search of P-base (Mielke 2008, Brohan \& Mielke 2016).

22 See Solé 2007 for a review of mechanical and controlled versions of the same types of phonological patterns. 
about what kinds of patterns are prototypical are shaped by the kinds of sound patterns we have been able to study, a sample that is biased toward sound patterns that involve acoustically distinct speech sounds.

Acoustic and articulatory studies by Ménard and colleagues $(2009,2013)$ illustrate the role of feedback in a different way. In these studies, sighted and congenitally blind speakers of French produced rounded and unrounded vowels. The sighted subjects used lip protrusion to a greater degree in production than blind subjects and produced rounded and unrounded vowels that were slightly farther apart in acoustic space. The blind speakers use tongue position to a greater degree to distinguish rounded and unrounded vowels. This indicates use of the trade-off between lip protrusion and tongue backing, both of which help achieve the low F2 and/or F3 characteristic of rounded vowels. Access to visual information is apparently necessary in order to achieve the degree of lip protrusion that is customary for French, but it is not the only way to achieve the acoustic target. A range of combinations of lip-protrusion and tongue-backing values can achieve similar acoustic results, but achieving the same visual result requires a particular combination of values. Similarly, the deaf subjects in the study by Matthies and colleagues (2008) exhibited variability in the acoustic properties of $/ \mathbf{x} /$, which was reduced after a year of auditory feedback with cochlear implants. The behavior of each of these pairs of groups of subjects depends on access to visual or auditory cues that would indicate a more precise production strategy that corresponds to the community norm. / $\mathbf{x} /$ allophony and $/ 1 /$ allophony differ in a similar way: /1/ allophony provides clear acoustic evidence of the contexts where the allophones are produced, and $/ \mathbf{I} /$ allophony generally does not, so users of $/ 1 /$ allophony have more feedback than users of $/ \mathbf{x} /$ allophony. We attribute the major differences between the two types of phenomena to this difference in feedback, and argue that this difference sheds light on phonetic naturalness and simplicity, two typical properties of sound patterns, as discussed in the rest of this section.

5.1. Phonetic naturalness. $/ \mathbf{x} /$ - and $/ 1 /$-allophony patterns both tend to be phonetically natural. In general, the constraints that recur across subjects and across languages have straightforward phonetic interpretations. For $/ \mathbf{x} /$, retroflexion rates are generally low next to segments that require the tongue tip to be somewhere other than where it needs to be for a retroflex consonant (a high front vowel, and lingual consonants, especially coronals). Postvocalic $/ \mathbf{x} /$ is retroflexed most frequently before $/ 1 /$, which in English is articulatorily and acoustically similar to a back vowel, and there is very little retroflexion in other postvocalic contexts. The tongue shape for bunched $/ \mathrm{d} /$ is similar to other 'bunched' segments such as $/ \mathrm{i} /, / \mathrm{J} /$, and $/ \mathrm{k} /$, next to which bunched $/ \mathrm{x} /$ often occurs. Retroflexion is more frequent in contexts that do not place conflicting demands on the tongue tip, such as word boundaries, labial consonants, back vowels, and /1/. It is quite often the case that recurrent sound patterns have phonetic motivations, and / $/ \mathrm{I} /$ and $/ \mathrm{l} / \mathrm{al}$ lophony are unremarkable in this respect. What is interesting is what these facts show about the relationship between phonetic naturalness and other typical properties of sound patterns. The phonetic naturalness is attributable to the phonetic precursors of the sound patterns, which are present regardless of what variant of the pattern ends up becoming conventional for a speech community or, in the case of $/ \mathbf{x} /$ allophony, ends up becoming conventional for one speaker.

5.2. Simplicity AND COMPLEXITy. While $/ \mathrm{a} /$ - and $/ 1 /$-allophony patterns both seem to employ similar sets of phonetically motivated constraints, many / $\mathbf{x} /$-allophony patterns are quite complex, in a way that most /1/-allophony patterns are not. Tables 5 and 6 show constraint-based grammars for eleven observed patterns of $/ \mathbf{x} /$ allophony and thirteen observed patterns of /1/ allophony. 
Table 5 shows all of the distinct constraint-based grammars for eleven observed patterns of $/ \mathbf{I} /$ allophony. ${ }^{23}$ Based on the observed constraints, it is possible to predict other allophony patterns we did not observe that would correspond to other rankings of these constraints, such as a speaker who retroflexes before back vowels but not /1/ (*CODA $\left.*_{\lrcorner} \mathrm{i},{ }^{*} \theta_{\beth 0}>*_{\mathrm{I}}, *_{1}>*_{\jmath}\right)$. It remains to be seen whether implicational relationships between contexts (e.g. retroflexion before /i/ implies retroflexion after linguals) would hold up with a larger data set.

In general, it requires more context-sensitive constraints to express speaker-level $/ \mathrm{A} /$-allophony patterns than to express language-level ///-allophony patterns. The nine subjects with categorical / $/ \mathrm{d} /$-allophony patterns all require between three and five context-sensitive constraints. So while no subject makes use of all the phonetically motivated constraints that are observed, using multiple constraints appears to be the rule rather than the exception for $/ \mathbf{d} /$ allophony. This proliferation of constraints is in stark contrast to /1/-allophony patterns. Of the seventeen languages with variation between clear and dark allophones of /1/, ten (63\%) require only one context-sensitive constraint, and five $(31 \%)$ require two constraints. Only one requires three constraints.

\begin{tabular}{|c|c|c|c|}
\hline \multicolumn{4}{|c|}{$\begin{array}{l}\text { SPEAKER(S) } \\
(n=2)\end{array}$} \\
\hline r19 & * coda & & $*[$ Cor $] \_$ \\
\hline r08 & & 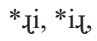 & $*_{x}[\mathrm{Cor}]$, \\
\hline r10 & *coda & $*$ il & \\
\hline r04 & *coda & $*_{\text {Ii }}$, & \\
\hline $\mathrm{r} 27$ & $* \operatorname{coda} t$ & * & \\
\hline r32 & $* \operatorname{coda}$ & $*$ il, & \\
\hline $\mathrm{r} 17$ & $* \operatorname{coda}$ & * & \\
\hline r06 & * coda & * & $*[$ Ling $] \_$ \\
\hline $\begin{array}{l}\mathrm{r} 01 \\
(n=16)\end{array}$ & $* \operatorname{coda}$ & $*_{i}$ il, & $*[$ Ling $] \succcurlyeq$ \\
\hline
\end{tabular}

CONSTRAINT RANKING

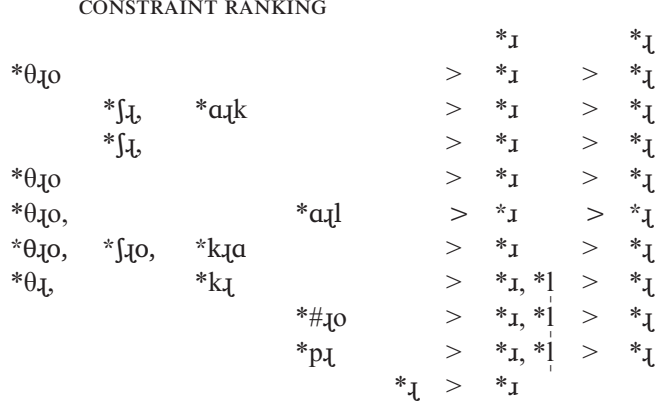

TABLE 5./r/ grammars.

LANGUAGE(s)

French, Italian, etc.

Abha Arabic

Kharia

Norwegian (some dialects)

B.E., Dutch, B.P., Mundari, Taos

Boumaa Fijian

Assyrian Neo-Aramaic

Alabama

Turkish, Kirghiz

Georgian

Jordanian Arabic

Buriat

Scottish English, American English, etc.

\begin{tabular}{|c|c|c|c|c|c|c|c|}
\hline & & ONSTRAII & RANKII & & & & \\
\hline & & & & $>$ & $* 1$ & $>$ & $* 1$ \\
\hline$* 1(\mathrm{~V}) \mathrm{C}^{\mathrm{f}}$ & & & & $>$ & $* 1$ & $>$ & $* 1$ \\
\hline$* \mathrm{ul} \#$ & & & & $>$ & $* 1$ & $>$ & $* 1$ \\
\hline$*$ coda $1 \vee$ ul\# & & & & $>$ & $* 1$ & $>$ & $* 1$ \\
\hline * coda 1 & & & & $>$ & $* 1$ & $>$ & $* 1$ \\
\hline$* l u$ & & & & $>$ & $* 1$ & $>$ & $* 1$ \\
\hline${ }^{*} \mathrm{C}^{\varsigma} 1$, & & $* 1 C^{\text {ई }}$ & & $>$ & $* 1$ & $>$ & $* 1$ \\
\hline *ulC & $>$ & $* 1 \mathrm{C}$ & & $>$ & $* 1$ & $>$ & * \\
\hline *lu, & & ul & & $>$ & $* 1$ & $>$ & $* 1$ \\
\hline *lu, & & $*$ coda 1 & & $>$ & $* 1$ & $>$ & *1 \\
\hline *kl, & & $*^{\mathrm{s}} 1$ & & $>$ & $* 1$ & $>$ & $* 1$ \\
\hline *1s & & & $>* 1$ & $>$ & $* 1$ & & \\
\hline & & & $* 1$ & $>$ & $* 1$ & & \\
\hline
\end{tabular}

TABLE 6. /1/ grammars.

23 These grammars could be augmented further to account for optionality in contexts where speakers produce both $/ \mathbf{I} /$ types, but as it is, it accounts for $98.1 \%$ of the data. Most of the remaining $1.9 \%$ is due to $\mathrm{r} 08$ and $\mathrm{r} 32$, who have several contexts with close to $50 \%$ tip-up $/ \mathrm{x} /$, and $\mathrm{r} 01$, whose contexts with infrequent retroflexion have been counted as retroflex to distinguish them from the contexts with no retroflexion. 
Furthermore, three of the four languages needing two constraints employ a pair of mirror-image constraints: Assyrian Neo-Aramaic with ${ }^{*} \mathrm{C}^{\S} 1$ and ${ }^{*} 1 \mathrm{C}^{\mathrm{f}}$, and Turkish and Kirghiz with *lu and *ul. If each of these pairs is treated as a single constraint concerned with adjacency but not direction, then Alabama, Georgian, and Jordanian Arabic are the only languages with $/ 1$-allophony patterns requiring more than one contextsensitive constraint.

Another difference between $/ \mathbf{x} /$ and $/ 1 /$ allophony concerns the constraints themselves: many of the $/ \mathbf{I} /$ constraints involve interactions between consonant and vowel contexts. For example, the effects of coronal consonants and /i/ appear to be multiplicative, and a large number of the constraints needed to describe $/ \mathbf{x} /$ allophony refer to particular consonants and vowels, a type of specificity that is not seen for $/ 1 /$ allophony.

These differences in complexity mean that /1/-allophony patterns draw upon fewer of the possible constraints than $/ \mathrm{x} /$-allophony patterns do, selecting smaller numbers of constraints, and apparently preferring broad constraints over specific ones. A bias toward a small number of broad constraints is understandable if we think of the convergence on a community norm as a process of koineization (see e.g. Siegel 1985, Trudgill 1986, Kerswill 2002). That is, going from a diverse set of individual phonetically motivated patterns to a single pattern is a possible outcome of language contact, summarized by Britain (1997:16):

The dialects which crystallize from contact scenarios are not only 'mixed,' incorporating elements from a number of the ingredient varieties, but are also KOINÉIZED; i.e., they contain relatively more unmarked structures, as well as features which demonstrate a regularization of the dialects in the initial mixture.

Britain (1997) analyzes the development of a Canadian-raising-like [ai] [əi] allophony pattern in the English Fens as a case of koineization. The Fens are the site of massive dialect contact on marshland that was reclaimed starting in the seventeenth century. The dialects in contact realized /ai/ as [ai] or [əi] in what may have seemed like a random distribution of phonetic realizations. What emerged was an allophonic pattern in which [əi] occurs before voiceless consonants and [ai] occurs elsewhere. Britain (p. 41) attributes this to second-generation children who 'rationalize the mixed speech of their parents and peers', leading to new linguistic norms for the third generation to follow.

We suggest that $/ 1 /$ allophony is different from $/ \mathbf{x} /$ allophony not just because its perceptibility encourages a single community norm, but also because the process of arriving at this norm favors patterns statable in terms of a small number of broad constraints. Idiosyncratic $/ \mathrm{x} /$-allophony patterns, by contrast, do not undergo this process and are free to be complex. This complexity goes hand in hand with speaker-specificity, and the ability of idiosyncratic sound patterns to be customized to the speaker. It is important to emphasize that the term 'koineization' is typically applied to contact situations where speakers of distinct but mutually intelligible language varieties find themselves in contact with each other and develop a new contact variety. In applying it to the case of idiosyncratic and shared phonological patterns, we are suggesting that individuals have the capacity to learn highly complex phonological patterns, but that familiar language-level phonological rules are all the result of contact. They are not derived from any one speaker's idiosyncratic phonetic motivations, but reflect a compromise. In the traditional dialect contact setting, the koineization process can be observed and features can be tracked. It would be difficult to directly observe the simplification process we are proposing to account for the difference between $/ \mathrm{x} /$ - and $/ \mathrm{l} /$-allophony patterns. $/ \mathrm{x} /$ allophony will never undergo anything like koineization because it is not sufficiently detectable to be shared by a community. For more conventional phonological patterns like the cases of /1/ allophony that we reported, the original koineization-like events would 
likely have occurred at the inception of sound change, which is notoriously difficult to observe (Weinreich et al. 1968, Janda \& Joseph 2003b, Baker et al. 2011). Our best evidence that typical phonological patterns show signs of simplification that is attributable to being shared by a community is that $/ \mathrm{A} /$ allophony reveals what is possible when phonological patterns are NOT shared by a community.

Phonological patterns that are shared by communities can also be quite complex, and Trudgill (2002) has suggested that the maintenance of complex phonological patterns is facilitated by isolated communities with dense social networks. One such complex pattern is the Philadelphia/æ/-tensing system, where /æ/ is realized as [عə] before $/ \mathrm{m} \mathrm{n} \mathrm{f} \theta$ s/ and in the words mad, bad, and glad (Labov 1994:Ch. 18). Payne (1976, 1980) examined the acquisition of this pattern by children growing up in a dialect contact situation in King of Prussia, a new community outside Philadelphia, and found that children who arrived before the age of nine were more likely to learn all the details of the pattern than children who arrived when they were older. Dinkin (2009:153-55) argues that the spread of the New York City /æ/-tensing pattern favored phonetically natural classes.

What all of these different types of patterns have in common is a phonetically complex substrate from which less complex phonological patterns are sometimes drawn. An excellent example of this comes from Gordon's (2002) study of syllable weight. Languages with quantity-sensitive stress systems may be sensitive to vowel length as well as to coda consonants, and different types of consonants contribute more or less to the perception of weight, with the expectation that sonorants, which are phonetically more vowel-like, would be more prone to contributing to the weight of a syllable, as compared to obstruents. Gordon showed that languages rarely make distinctions fine enough to include only certain consonants, even though it would be phonetically sensible to do so. Rather, languages typically make weight distinctions that either include or exclude consonants. The choice of whether to include consonants is influenced by the ratio of sonorants to obstruents in the language; that is, languages with a greater proportion of sonorant consonants are more likely to be languages in which all consonants contribute to syllable weight. The preference for simple quantity-sensitivity systems can be interpreted as an analytic bias (in the terminology of Moreton 2008) that operates on an individual level, or an emergent consequence of contact between individuals. Either interpretation predicts a world in which phonological patterns tend to be simpler than their phonetic precursors. We present the data from individual $/ \mathrm{I} /$-allophony patterns as evidence that this bias is due to contact between individuals and the development of shared phonological patterns rather than an individual-level bias against complex patterns.

5.3. SPEAKER-SPECIFICITY. Another way in which / $/ \mathrm{d} /$ allophony stands out from other phonological patterns is its speaker-specificity. We argue that speaker-specificity is permitted because / $/ \mathrm{d}$ /allophony's covert nature prevents convergence, but a second question is why speakers do not independently arrive at the same phonetically motivated patterns anyway. We appeal to two sources of interspeaker differences to account for this variation: individual acquisition trajectories and individual articulatory motivations.

Tiede and colleagues (2011) interpreted adults' abilities to change / $\mathrm{x} /$ strategies in order to cope with a dental appliance as evidence of articulatory experience gained during acquisition. Such exploration could be key to understanding the nature of adult variation. In $\S 3.4$, we identified a partial hierarchy of phonological contexts based on compatibility with retroflexion. One way that hierarchies like this have been dealt with in the OT literature is with a constraint that 'floats' to different points within the hierarchy (Nagy \& Reynolds 1997). Here this means setting different cut-off points for bunched and retroflex $/ \mathrm{I} /$ at different points in the hierarchy for different speakers. One 
way of arriving at speaker-specific cut-off points within a general hierarchy is by exploration during acquisition. Learning English $/ \mathbf{x}$ / involves learning one or more sets of lingual and labial gestures that may or may not be stable across phonological contexts. We can speculate that a child who first succeeds in making an adult-like $/ \mathbf{I} /$ in wordinitial prevocalic position could use retroflex $/ \mathbf{x}$, and then may attempt to use the same strategy in increasingly challenging contexts until eventually either succeeding in all of them or beginning to use bunched $/ \mathbf{x} /$. In this scenario, adult $/ \mathbf{x} /$ patterns depend on where the search starts and at what point (if any) a new strategy is introduced.

Magloughlin (2016) conducted a longitudinal ultrasound study of four speakers of Canadian English aged three to six, including a set of apparently identical twins who produced completely different $/ \mathrm{x} /$ types. This twin behavior supports the idea that exploration, rather than a deterministic algorithm, drives the development of adult $/ \mathrm{x} /$ patterns. Another child showed a development trajectory that was consistent with her dominant $/ \mathrm{J} /$ strategy: at four years, three months she produced adult-like $/ \mathbf{I} /$ with a bunched tongue posture in postvocalic and syllabic contexts, [w]-like/x/ in most prevocalic contexts, and near-adult-like/x/ in prevocalic contexts following coronal consonants. Magloughlin observes that the child successfully produced $/ \mathbf{I} /$ in contexts where her dominant strategy (bunched) is most frequent among adults, and that her non-adult-like $/ \mathrm{d} / \mathrm{s}$ were produced in contexts where many adults produce retroflex $/ \mathrm{d} /$. The earliest adult-like prevocalic $/ \mathrm{x} /$ occurred after coronal consonants, which may facilitate bunching before a general prevocalic strategy is developed. Six months later this child had developed bunched $/ \mathrm{x} /$ in all contexts, which is the most frequent adult pattern. If she had developed retroflex $/ \mathrm{x} /$ in one of the delayed contexts, there are eight subjects in the current study whose allophonic patterns she could have matched.

The adult allophony patterns are broadly consistent with a gestural compatibility hierarchy in which different learners arrive at different cut-off points depending on their experience exploring the articulatory space in different contexts. This is especially true for the contexts with the most clear biomechanical bases for particular $/ \mathrm{x} / \mathrm{strategies:}$ there are virtually no exceptions to the $/ \mathrm{i} / \rightarrow / \mathrm{a} /$ and coda $\rightarrow$ onset implicational relationships for retroflexion. But there are several speaker-specific gaps that seem to reflect speakerspecific phonetic pressures. The clearest evidence for this comes from the subjects who retroflex in opposite contexts (illustrated above in Fig. 9): since r17 has an apical / $/$, he apparently learned to produce $/ \mathrm{x} /$ with a hierarchy in which $/ \mathrm{S} /$ is relatively favorable to retroflexion. Since $\mathrm{r} 08$ 's retroflex $/ \mathrm{x} /$ has a raised tongue body, she apparently learned to produce $/ \mathrm{s} /$ with a hierarchy in which $/ \mathrm{k} /$ is relatively favorable to retroflexion. Importantly, the articulatory differences that motivate these different phonetic motivations (apical / $/$ / and dorsum-raising-retroflex/x/) are observed in contexts other than the ones where they account for idiosyncratic reversals of the general bunched/retroflex compatibility hierarchy. Learning $/ \mathrm{x} /$ strategies is an individual process, and the phonetic backdrop against which phonological patterns are learned can vary from speaker to speaker. The broad similarities between subjects are attributable to similar but not identical hierarchies of gestural compatibility. Consistent articulatory differences in the contexts where / $/ \mathrm{A}$ / occurs can lead to speaker-specific differences of a type that is not typically seen in overt allophony patterns.

In the absence of input motivating a particular allophony pattern, each speaker must create a new idiosyncratic sound pattern. These patterns resemble each other to the extent that variants can be produced with a human vocal tract, and they have the same acoustic result (e.g. low F3). These idiosyncratic sound patterns are the POOL OF VARIA- 
TION from which new conventional patterns can be drawn, ${ }^{24}$ and $/ \mathbf{x} /$ allophony is stuck in this pool. It is stalled at an early stage of its development, with no convergence on a common pattern and no simplification. Variants of the pattern still tend to be phonetically natural.

Speaker-specific articulatory needs can be accommodated by idiosyncratic patterns of $/ \mathbf{x} /$ allophony in ways that would not be possible with typical sound patterns. Pierrehumbert (2001) argues that phonological constraints tend to be as coarse-grained as they typically are because they have to be stable across speakers with different lexicons that exhibit different statistical patterns. We can add that phonological constraints that apply to a community of speakers also need to be coarse-grained in order to be stable across speakers with idiosyncratic phonetic pressures and acquisition paths. What is natural for $\mathrm{r} 08$ is not natural for $\mathrm{r} 17$, and vice versa, and if a community-wide allophony pattern could emerge, it probably would not reflect any of these individuals' idiosyncrasies, and it could not reflect all of them.

$/ \mathbf{x} /$ allophony is different from many other known sound patterns because of its speaker-specificity and complexity, and these facts, while interesting for $/ \mathrm{x} /$ 's own sake, have perhaps more interesting implications for other sound patterns, because the nature of $/ \mathbf{x} /$ provides insight into how phonetic naturalness is involved in phonological patterns, and how naturalness is separate from simplicity. This interpretation supports the view that phonetically natural sound patterns (and their characteristic properties) emerge through the conventionalization of phonetic effects (Hyman 1977, Ohala 1981, 1993, Ladefoged 1984, Labov 1994, 2001, Blevins \& Garrett 1998, Bybee 1998, Hume \& Johnson 2001, Hale 2003, Janda 2003, Janda \& Joseph 2003a, Kiparsky 2003, Blevins 2004, inter alia). The typical development of phonetically motivated phonological patterns involves koineization-like convergence on a relatively simple compromise pattern that may not be an exact match of any of the input patterns.

6. Conclusions. We have shown that /1/ allophony and $/ \mathrm{x} /$ allophony both have an apparent articulatory basis, and both are mostly phonetically grounded. Importantly, /1/ allophony involves a perceptible difference, but $/ \mathrm{d} /$ allophony involves a virtually imperceptible difference. We have argued that as a consequence, $/ 1 /$-allophony patterns are shared by communities of speakers but / $/ \mathbf{I}$-allophony patterns are not. /1/-allophony patterns are also relatively simple in comparison to $/ \mathrm{d} /$-allophony patterns.

These results have shown that different sound patterns can emerge in response to the same phonetic motivation, depending on which variant is ultimately conventionalized, and that different speakers can have different phonetic motivations, but the norm is sound patterns that reflect a compromise based on other speakers' phonetic motivations. Sound patterns can be simultaneously phonetically natural and complex, and phonetic naturalness and simplicity can be distinct byproducts of the development of a sound pattern. We attribute phonetic naturalness to the individual and simplicity to individuallevel contact at or shortly after the inception of sound change, and we hope that future work will reveal more about the dynamics of the early stages of sound-pattern development. This analysis was made possible by tools of laboratory phonology and a framework in which sound patterns are understood as products of the interaction over time of many different language-internal and language-external factors. We hope that further empirical investigation into the hidden details of sound patterns, combined with a con-

24 'Sound change is drawn from a pool of synchronic variation' (Ohala 1989). 
sideration of the phonetic, psycholinguistic, and social mechanisms that interact to produce these patterns, can provide greater insight into where phonological patterns come from and how they work.

ApPendix A: Syllabic/a/

Figure A1 shows the retroflexion rates for syllabic/x/. Seven of the eight subjects who produced any postvocalic $/ \mathrm{I} /$ as retroflex also produced at least some syllabic $/ \mathrm{I} /(/ \mathrm{r} /)$ as retroflex. None of the other subjects produced any retroflex syllabic / $\mathrm{x} /$. Two subjects ( $\mathrm{r} 19$ and $\mathrm{r} 08$ ) produce retroflex only before $/ 1 /$, which raises the same syllable-structure questions as postvocalic pre-/1//x/. r04 retroflexes in a superset of these contexts, and $\mathrm{r} 27$ and $\mathrm{r} 32$ retroflex in different subsets.

\section{Retroflexion rate by subject and context}

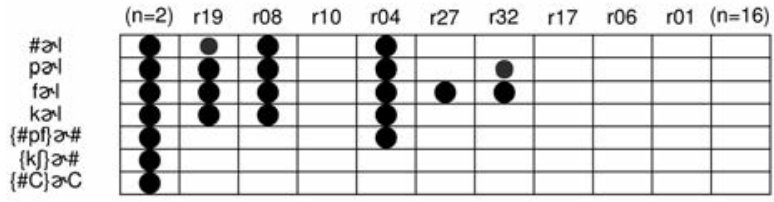

FIgURE A1. Retroflexion rates for syllabic / $/ \mathrm{d} /(\mathrm{\gamma} /)$

ApPendix B: STIMULI

\begin{tabular}{|c|c|c|c|c|c|c|}
\hline Prevocalic /x/: & $\begin{array}{l}\text { rod } \\
\text { road } \\
\text { reed } \\
\text { prop } \\
\text { prose } \\
\text { preen } \\
\text { trot } \\
\text { troll } \\
\text { tree } \\
\text { crop } \\
\text { crow } \\
\text { creek }\end{array}$ & $\begin{array}{l}\text { rot } \\
\text { wrote } \\
\text { reek } \\
\text { prom } \\
\text { probe } \\
\text { preach } \\
\text { trod } \\
\text { trope } \\
\text { treat } \\
\text { cross } \\
\text { croak } \\
\text { creep }\end{array}$ & $\begin{array}{l}\text { rock } \\
\text { Rome } \\
\text { real } \\
\text { prawn } \\
\text { pro } \\
\text { priest } \\
\text { trawl } \\
\text { troe } \\
\text { trees } \\
\text { crock } \\
\text { crone } \\
\text { creed }\end{array}$ & $\begin{array}{l}\text { rob } \\
\text { rope } \\
\text { ream } \\
\text { frog } \\
\text { froze } \\
\text { freeze } \\
\text { throb } \\
\text { throat } \\
\text { three } \\
\text { Shrop } \\
\text { shrove } \\
\text { shriek }\end{array}$ & $\begin{array}{l}\text { wrong } \\
\text { roach } \\
\text { reap } \\
\text { frost } \\
\text { fro } \\
\text { free } \\
\text { thrall } \\
\text { throe } \\
\text { threes } \\
\text { Shrock } \\
\text { Shrow } \\
\text { Shree }\end{array}$ & $\begin{array}{l}\text { froth } \\
\text { Froke } \\
\text { freak } \\
\text { throng } \\
\text { throve } \\
\text { Threet }\end{array}$ \\
\hline Postvocalic $/ \mathrm{x} /$ : & $\begin{array}{l}\text { car } \\
\text { tear } \\
\text { more } \\
\text { harp } \\
\text { warp } \\
\text { tart } \\
\text { wart } \\
\text { park } \\
\text { pork } \\
\text { Carl }\end{array}$ & $\begin{array}{l}\text { bar } \\
\text { year } \\
\text { core } \\
\text { sharp } \\
\text { Thorp } \\
\text { start } \\
\text { sport } \\
\text { shark } \\
\text { fork } \\
\text { gnarl }\end{array}$ & $\begin{array}{l}\text { far } \\
\text { peer } \\
\text { door } \\
\text { carp } \\
\text { Morp } \\
\text { part } \\
\text { port } \\
\text { dark } \\
\text { cork } \\
\text { snarl }\end{array}$ & $\begin{array}{l}\text { scar } \\
\text { near } \\
\text { score } \\
\text { scarf } \\
\text { wharf } \\
\text { hearth } \\
\text { north } \\
\text { arch } \\
\text { torch } \\
\text { whorl }\end{array}$ & $\begin{array}{l}\text { tar } \\
\text { clear } \\
\text { tore } \\
\text { arf } \\
\text { dwarf } \\
\text { Carth } \\
\text { forth } \\
\text { March } \\
\text { porch } \\
\text { chorl }\end{array}$ & $\begin{array}{l}\text { barf } \\
\text { morph } \\
\text { Parth } \\
\text { fourth } \\
\text { starch } \\
\text { scorch }\end{array}$ \\
\hline Syllabic /x/: & $\begin{array}{l}\text { er } \\
\text { perp } \\
\text { earth } \\
\text { Kirk } \\
\text { curl }\end{array}$ & $\begin{array}{l}\text { purr } \\
\text { perf } \\
\text { Perth } \\
\text { shirk }\end{array}$ & $\begin{array}{l}\text { fur } \\
\text { turf } \\
\text { firth } \\
\text { perch }\end{array}$ & $\begin{array}{l}\text { cur } \\
\text { pert } \\
\text { irk } \\
\text { earl }\end{array}$ & $\begin{array}{l}\text { sure } \\
\text { curt } \\
\text { perk } \\
\text { pearl }\end{array}$ & $\begin{array}{l}\text { urp } \\
\text { shirt } \\
\text { Turk } \\
\text { furl }\end{array}$ \\
\hline Fillers: & $\begin{array}{l}\text { bag } \\
\text { chief } \\
\text { goat } \\
\text { page } \\
\text { shake } \\
\text { take }\end{array}$ & $\begin{array}{l}\text { bog } \\
\text { claim } \\
\text { Jeep } \\
\text { pail } \\
\text { sheep } \\
\text { tape }\end{array}$ & $\begin{array}{l}\text { cash } \\
\text { dog } \\
\text { lack } \\
\text { pat } \\
\text { shop } \\
\text { took }\end{array}$ & $\begin{array}{l}\text { cash } \\
\text { fast } \\
\text { least } \\
\text { pop } \\
\text { snake }\end{array}$ & $\begin{array}{l}\text { cat } \\
\text { field } \\
\text { mouse } \\
\text { sail } \\
\text { sock }\end{array}$ & $\begin{array}{l}\text { catch } \\
\text { fish } \\
\text { pack } \\
\text { seal } \\
\text { steal }\end{array}$ \\
\hline
\end{tabular}




\section{REFERENCES}

Al-Sughayer, Khalil Ibrahim. 1990. Aspects of comparative Jordanian and Modern Standard Arabic phonology. Ann Arbor: University Microfilms International.

Alwan, Abeer A.; Shrikanth S. Narayanan; and Katherine Haker. 1997. Toward articulatory-acoustic models for liquid approximants based on MRI and EPG data, part II: The rhotics. Journal of the Acoustical Society of America 101.1078-89. DOI: 10.1121 /1.417972.

Archangeli, Diana; Adam Baker; and Jeff Mielke. 2011. Categorization and features: Evidence from American English / $\mathrm{x} /$. Where do phonological contrasts come from?, ed. by G. N. Clements and Rachid Ridouane, 173-96. Amsterdam: John Benjamins.

Archangeli, Diana, and Jeff Berry. 2010. Dark and light /1/s in Georgian. Paper presented at UltraFest V, Haskins Laboratories, New Haven, CT, March.

Archangeli, Diana; Jeff Berry; Colin Gorrie; Lionel Mathieu; Jessamyn Schertz; and JAE Hyun Sung. 2010. Timing of tongue tip and dorsum gestures in French and Georgian /1/s. Poster presented at LabPhon 12.

Baker, Adam. 2005. Palatoglossatron 1.0. Tucson: University of Arizona. Online: http:// dingo.sbs.arizona.edu/ apilab/pdfs/pgman.pdf.

Baker, AdAm; Diana ArChangeli; and JefF Mielke. 2011. Variability in English s-retraction suggests a solution to the actuation problem. Language Variation and Change 23. 347-74. DOI: 10.1017/S0954394511000135.

BILGIRI, H. S. 1965. Kharia: Phonology, grammar, and vocabulary. Poona: Deccan College Postgraduate and Research Institute.

Blevins, Juliette. 2004. Evolutionary phonology. Cambridge: Cambridge University Press.

Blevins, Juliette, and Andrew Garrett. 1998. The origins of consonant-vowel metathesis. Language 74.508-56. DOI: 10.2307/417792.

Boersma, Paul, and David Weenink. 2007. Praat: Doing phonetics by computer. Online: http://www.praat.org.

Boolj, Geert. 1999. The phonology of Dutch. Oxford: Oxford University Press.

Boyce, Suzanne, and CAROL Y. ESPY-WiLson. 1997. Coarticulatory stability in American English /r/. Journal of the Acoustical Society of America 101.3741-53. DOI: 10.1121/1 .418333 .

BRITAIN, DAVID. 1997. Dialect contact and phonological reallocation: 'Canadian raising' in the English Fens. Language in Society 26.15-46. DOI: 10.1017/S0047404500019394.

Brohan, Anthony, and Jeff Mielke. 2016. Frequent segmental alternations in P-base 3. Cambridge, MA: MIT, and Raleigh: North Carolina State University, MS.

Browman, Catherine, and Louis Goldstein. 1995. Gestural syllable position effects in American English. Producing speech: Contemporary issues: For Katherine Safford Harris, ed. by Fredericka Bell-Berti and Lawrence J. Raphael, 510-20. Woodbury, NY: American Institute of Physics.

Bybee, Joan. 1998. Usage-based phonology. Functionalism and formalism in linguistics, vol. 1: General papers, ed. by Michael Darnell, Edith A. Moravcsik, Michael Noonan, Frederick J. Newmeyer, and Kathleen Wheatley, 211-42. Amsterdam: John Benjamins.

Campbell, Fiona; Bryan Gick; Ian Wilson; and Eric Vatikiotis-Bateson. 2010. Spatial and temporal properties of gestures in North American English /r/. Language and Speech 53.49-69. DOI: 10.1177/0023830909351209.

Carignan, Christopher; Jeff Mielke; and Robin Dodsworth. 2016. Tongue trajectories in North American English short-a tensing. The future of dialects: Selected papers from Methods in Dialectology XV (Language variation 1), ed. by Marie-Hélène Côté, Remco Knooihuizen, and John Nerbonne, 313-19. Berlin: Language Science Press.

CATFORD, J. C. 1988. A practical introduction to phonetics. Oxford: Clarendon.

Chambers, J. K.; Peter Trudgill; and Natalie Schilling-Estes (eds.) 2002. The handbook of language variation and change. Oxford: Blackwell.

Chomsky, Noam, and Morris Halle. 1968. The sound pattern of English. New York: Harper and Row.

Cook, Rev. Walter Anthony. 1974. Structure of the Mundari language. Ann Arbor: Xerox University Microfilms.

Delattre, Pierre. 1969. L'/r/ parisien et autres sons du pharynx. The French Review 43.522. Online: http://www.jstor.org/stable/386726. 
Delattre, Pierre, and Donald C. Freeman. 1968. A dialect study of American $r$ 's by X-ray motion picture. Linguistics 44.29-68. DOI: 10.1515/ling.1968.6.44.29.

Derrick, Donald, and Bryan Gick. 2008. Quantitative analysis of subphonemic flap/tap variation in NAE. Canadian Acoustics 36.162-63. Online: http://jcaa.caa-aca.ca/index .php/jcaa/article/view/2088.

DERrick, DonalD, and Bryan Gick. 2011. Individual variation in English flaps and taps: A case of categorical phonetics. Canadian Journal of Linguistics 56.307-19. DOI: 10 $.1353 / \mathrm{cj} 1.2011 .0024$.

Dinkin, AARON. 2009. Dialect boundaries and phonological change in upstate New York. Philadelphia: University of Pennsylvania dissertation.

Dixon, R. M. W. 1988. A grammar of Boumaa Fijian. Chicago: University of Chicago Press.

ESPY-Wilson, CAROL, and SuZANNE BoyCE. 1994. Acoustic differences between 'bunched' and 'retroflex' variants of American English /r/. Journal of the Acoustical Society of America 95.2823. DOI: 10.1121/1.409691.

Espy-Wilson, Carol; Suzanne Boyce; Michel Jackson; Shrikanth Narayanan; and Abeer Alwan. 2000. Acoustic modeling of American English /r/. Journal of the Acoustical Society of America 108.343-56. DOI: 10.1121/1.429469.

Feldman, D. 1972. On utterance-final [ł] and [u] in Portuguese. Papers in linguistics and phonetics to the memory of Pierre Delattre, ed. by Albert Valdman, 129-41. The Hague: Mouton.

Fromkin, Victoria, and Peter Ladefoged. 1966. Electromyography in speech research. Phonetica 15.219-42. DOI: 10.1159/000258547.

Gick, BRYAn. 1999. A gesture-based account of intrusive consonants in English. Phonology 16.29-54.

Gick, Bryan; Fiona Campbell; Sunyoung OH; and Linda Tamburri-Watt. 2006. Toward universals in the gestural organization of syllables: A cross-linguistic study of liquids. Journal of Phonetics 34.49-72. DOI: 10.1016/j.wocn.2005.03.005.

Gordon, Matthew J. 2002. A phonetically driven account of syllable weight. Language 78.51-80. DOI: 10.1353/lan.2002.0020.

Guenther, Frank; Carol Espy-Wilson; Suzanne Boyce; Melanie Matthies; Majid ZANDIPOUR; and Joseph Perkell. 1999. Articulatory tradeoffs reduce acoustic variability during American English /r/ production. Journal of the Acoustical Society of America 105.2854-65. DOI: 10.1121/1.426900.

Hagiwara, Robert. 1995. Acoustic realizations of American /r/ as produced by women and men. UCLA Working Papers in Phonetics 90.1-187. Online: http://escholarship.org/uc /item/8779b7gq.

Hale, MARK. 2003. Neogrammarian sound change. In Joseph \& Janda, 343-68.

Halle, Morris. 1959. The sound pattern of Russian. The Hague: Mouton.

Herrity, Peter. 2000. Slovene: A comprehensive grammar. New York: Routledge.

Hueber, Thomas; Guido Aversano; Gérard Chollet; Bruce Denby; Gérard Dreyfus; Yacine Oussar; Pierre Roussel; and Maureen Stone. 2007. Eigentongue feature extraction for an ultrasound-based silent speech interface. IEEE International Conference on Acoustics, Speech and Signal Processing, Honolulu, 1245-48. DOI: 10 .1109/ICASSP.2007.366140.

Hume, Elizabeth V., and Keith Johnson. 2001. A model of the interplay of speech perception and phonology. The role of speech perception in phonology, ed. by Elizabeth $\mathrm{V}$. Hume and Keith Johnson, 3-26. New York: Academic Press.

Hyman, Larry. 1977. Phonologization. Linguistic studies presented to Joseph H. Greenberg, ed. by Alphonse Juilland, 407-18. Saratoga: Anna Libri.

Jakobson, Roman; C. Gunnar M. Fant; and Morris Halle. 1952. Preliminaries to speech analysis: The distinctive features and their correlates. Cambridge, MA: MIT Press.

JANDA, RichaRd D. 2003. 'Phonologization' as the start of dephoneticization - or, on sound-change and its aftermath: Of extension, generalization, lexicalization, and morphologization. In Joseph \& Janda, 401-22.

Janda, Richard D., and Brian D. Joseph. 2003a. On language, change, and language change - or, of history, linguistics, and historical linguistics. In Joseph \& Janda, 3180 .

JANDA, Richard D., and Brian D. Joseph. 2003b. Reconsidering the canons of soundchange: Towards a big bang theory. Historical linguistics 2001: Selected papers from 
the 15th International Conference on Historical Linguistics, Melbourne, 13-17 August 2001, ed. by Barry J. Blake and Kate Burridge, 205-19. Amsterdam: John Benjamins.

JoSEPH, BRIAN D., and RICHARD D. JANDA (eds.) 2003. The handbook of historical linguistics. Oxford: Blackwell.

Kent, R. D. 1985. Normal aspects of articulation. Articulation and phonological disorders, ed. by John Bernthal and Nicholas Bankson, 157-68. Boston: Allyn and Bacon.

Kerswill, Paul. 2002. Koineization and accommodation. In Chambers et al., 669-702.

KIPARSKY, PAUL. 2003. The phonological basis of sound change. In Joseph \& Janda, 313-42.

Kristoffersen, GJert. 2007. The phonology of Norwegian. Oxford: Oxford University Press.

Labov, William. 1994. Principles of linguistic change, vol. 1: Internal factors. Oxford: Blackwell.

Labov, William. 2001. Principles of linguistic change, vol. 2: Social factors. Oxford: Blackwell.

Ladefoged, Peter. 1957. Use of palatography. Journal of Speech and Hearing Disorders 22.764-74. DOI: $10.1044 /$ jshd.2205.764.

Ladefoged, Peter. 1972. Phonetic prerequisites for a distinctive feature theory. Papers in linguistics and phonetics to the memory of Pierre Delattre, ed. by Albert Valdman, 273-86. The Hague: Mouton.

Ladefoged, Peter. 1984. 'Out of chaos comes order': Physical, biological, and structural patterns in phonetics. Proceedings of the 10th International Congress of Phonetic Sciences (ICPhS), Utrecht, 83-95.

LEHISTE, ILSE. 1962. Acoustical characteristics of selected English consonants. Ann Arbor: University of Michigan Communication Sciences Laboratory.

LEWIS, GEOFFREY L. 1967. Turkish grammar. Oxford: Clarendon.

Lindau, Mona. 1985. The story of /r/. Phonetic linguistics: Essays in honor of Peter Ladefoged, ed. by Victoria A. Fromkin, 157-68. Orlando, FL: Academic Press.

LUPARDUS, KAREN JACQUE. 1982. The language of the Alabama Indians. Ann Arbor: University Microfilms International.

MacKay, Ian R. A. 1977. Tenseness in vowels: An ultrasonic study. Phonetica 34.325-51. DOI: $10.1159 / 000259907$.

Magloughlin, LyRA. 2016. Accounting for variability in North American English / $/ \mathrm{x} / \mathrm{:}$ Evidence from children's articulation. Journal of Phonetics 54.51-67. DOI: 10.1016/j .wocn.2015.07.007.

Matthies, Melanie L.; Frank H. Guenther; Margaret Denny; Joseph S. Perkell; Ellen Burton; Jennell Vick; Harlan Lane; Mark Tiede; and Majid Zandipour. 2008. Perception and production of / $\mathrm{r} /$ allophones improve with hearing from a cochlear implant. Journal of the Acoustical Society of America 124.3191-3202. DOI: 10 $.1121 / 1.2987427$.

Ménard, Lucie; Sophie Dupont; Shari R. Baum; and Jérôme Aubin. 2009. Production and perception of French vowels by congenitally blind adults and sighted adults. Journal of the Acoustical Society of America 126.1406-14. DOI: 10.1121/1.3158930.

Ménard, Lucie; Corinne Toupin; Shari R. Baum; Serge Drouin; Jérôme Aubin; and MARK Tiede. 2013. Acoustic and articulatory analysis of French vowels produced by congenitally blind adults and sighted adults. Journal of the Acoustical Society of America 134.2975-87. DOI: 10.1121/1.4818740.

Michelson, Karin Eva. 1983. A comparative study of accent in the Five Nations Iroquoian languages. Ann Arbor: University Microfilms International.

Mielke, JefF. 2008. The emergence of distinctive features. Oxford: Oxford University Press.

Mielke, JefF; AdAm Baker; and Diana ArChangeli. 2010. Variability and homogeneity in American English / $\mathrm{A} /$ allophony and /s/ retraction. Laboratory phonology 10: Variation, detail, and representation, ed. by Cécile Fougeron, Barbara Kühnert, Mariapaola D’Imperio, and Nathalie Vallee, 699-719. Berlin: Mouton de Gruyter.

Mielke, JefF; Adam Baker; Diana Archangeli; and Sumayya Racy. 2005. Palatron: A technique for aligning ultrasound images of the tongue and palate. Coyote Papers: Working Papers in Linguistics, Linguistic Theory at the University of Arizona 14.96107. Online: http://coyotepapers.sbs.arizona.edu/CPXIV.htm.

Moreton, Elliott. 2008. Analytic bias and phonological typology. Phonology 25.83-127. DOI: $10.1017 /$ S0952675708001413. 
NAGY, NAOMI, and Bill ReYNOLDS. 1997. Optimality theory and variable word-final deletion in Faetar. Language Variation and Change 9.37-55. DOI: 10.1017/S0954394500 001782.

Nakshabandi, Anwar Mohammed H. 1988. A descriptive study of the phonology and morphology of the Abha dialect. Ann Arbor: University Microfilms International.

Narayanan, Shrikanth S.; Abeer A. Alwan; and Katherine Haker. 1997. Toward articulatory-acoustic models for liquid approximants based on MRI and EPG data, part I: The laterals. Journal of the Acoustical Society of America 101.1064-77. DOI: 10.1121 /1.418030.

Ngunga, Armindo. 2000. Phonology and morphology of the Ciyao verb. Stanford, CA: CSLI Publications.

Odisho, Edward Y. 1988. Sound system of Modern Assyrian (Neo-Aramaic). Wiesbaden: Harrassowitz.

Ohala, John J. 1981. The listener as a source of sound change. Chicago Linguistic Society (Parasession on language and behavior) 17.2.178-203.

Ohala, John J. 1989. Sound change is drawn from a pool of synchronic variation. Language change: Contributions to the study of its causes (Trends in linguistics, studies and monographs 43), ed. by Leiv Egil Breivik and Ernst Håkon Jahr, 173-98. Berlin: Mouton de Gruyter.

Ohala, John J. 1993. Sound change as nature's speech perception experiment. Speech Communication 13.155-61. DOI: 10.1016/0167-6393(93)90067-U.

Ong, Darryl, and Maureen Stone. 1998. Three-dimensional vocal tract shapes in $/ \mathrm{r} /$ and /1/: A study of MRI, ultrasound, electropalatography, and acoustics. Phonoscope $1.1-13$.

Payne, Arvilla. 1976. The acquisition of the phonological system of a second dialect. Philadelphia: University of Pennsylvania dissertation.

Payne, Arvilla. 1980. Factors controlling the acquisition of the Philadelphia dialect by out-of-state children. Locating language in time and space, vol. 1, ed. by William Labov, 143-78. New York: Academic Press.

PierReHUmbert, JANET. 2001. Why phonological constraints are so coarse-grained. Language and Cognitive Processes (Special issue on spoken word access processes) 16.69198. DOI: 10.1080/01690960143000218.

PopPe, NichOlas. 1960. Buriat grammar. Bloomington: Indiana University.

Poppe, Nicholas, and Raymond J. Hebert. 1963. Kirghiz manual. Bloomington: Indiana University, and The Hague: Mouton.

Pouplier, Marianne, and Phillip Hoole. 2013. Comparing principal component analysis of ultrasound images with contour analyses in a study of tongue body control during German coronals. Paper presented at Ultrafest VI, Edinburgh, November.

Prince, Alan, and Paul Smolensky. 2008. Optimality theory: Constraint interaction in generative grammar. Oxford: Blackwell.

ReCASENS, DANiel, and Aina Espinosa. 2005. Articulatory, positional and coarticulatory characteristics for clear /1/ and dark /1/: Evidence from two Catalan dialects. Journal of the International Phonetic Association 35.1-25. DOI: 10.1017/S0025100305001 878.

RubaCh, JERZy. 1993. The lexical phonology of Slovak. Oxford: Clarendon.

RupP, JAmes E. 1989. Lealao Chinantec syntax: Studies in Chinantec languages, vol. 2. Arlington: Summer Institute of Linguistics and the University of Texas at Arlington.

Scobbie, James M.; Koen Sebregts; and Jane Stuart-Smith. 2006. From subtle to gross variation: An ultrasound tongue imaging study of Dutch and Scottish English /r/. Poster presented at LabPhon 10.

Shriberg, Lawrence D., and R. D. Kent. 1995. Clinical phonetics. Boston: Allyn \& Bacon.

Siegel, JefF. 1985. Koines and koineization. Language in Society 14.357-78. DOI: 10.1017 /S0047404500011313.

Solé, MARIA-Josep. 2007. Controlled and mechanical properties in speech. Experimental approaches to phonology, ed. by Maria-Josep Solé, Patrice Speeter Beddor, and Manjari Ohala, 302-21. Oxford: Oxford University Press.

Sproat, Richard, and Osamu Fujimura. 1993. Allophonic variation in English /1/ and its implications for phonetic implementation. Journal of Phonetics 21.291-311. 
Stavness, Ian; Bryan Gick; Donald Derrick; and Sidney Fels. 2012. Biomechanical modeling of English /r/ variants. Journal of the Acoustical Society of America 131. EL355-EL360. DOI: 10.1121/1.3695407.

Stevens, Kenneth N. 1972. The quantal nature of speech: Evidence from articulatoryacoustic data. Human communication: A unified view, ed. by Edward E. David and Peter B. Denes, 51-66. New York: McGraw Hill.

Stevens, Kenneth N. 1999. Acoustic phonetics. Cambridge, MA: MIT Press.

Stone, Maureen. 2005. A guide to analysing tongue motion from ultrasound images. Clinical Linguistics and Phonetics 19.455-502. DOI: 10.1080/02699200500113558.

Stone, Maureen; B. Sonies; Thomas Shawker; G. Weiss; and L. Nadel. 1983. Analysis of real-time ultrasound images of tongue configuration using a grid-digitizing system. Journal of Phonetics 11.207-18.

Tiede, Mark K.; Suzanne E. Boyce; Carol Y. Espy-Wilson; and Vincent L. Gracco. 2011. Variability of North American English /r/ production in response to palatal perturbation. Speech motor control: New developments in basic and applied research, ed. by Ben Maassen and Pascal van Lieshout, 53-67. Oxford: Oxford University Press.

Tiede, Mark K.; Suzanne E. Boyce; Christy K. Holland; and K. Ann Choe. 2004. A new taxonomy of American English/r/ using MRI and ultrasound. Journal of the Acoustical Society of America 115.2633-34. DOI: 10.1121/1.4784878.

Trager, George L. 1948. Taos I: A language revisited. International Journal of American Linguistics 14.155-60. Online: http://www.jstor.org/stable/1263040.

Trudgill, Peter (ed.) 1986. Dialects in contact. Oxford: Blackwell.

Trudgill, Peter. 2002. Linguistic and social typology. In Chambers et al., 305-20.

Tschenkeli, Kita. 1958. Einführung in die Georgische Sprache, Band 1. Zürich: Amirani.

Twist, Alina; Adam Baker; Jeff Mielke; and Diana Archangeli. 2007. Are 'covert'/a/ allophones really indistinguishable? Penn Working Papers in Linguistics 13.2. Online: http://repository.upenn.edu/pwpl/vol13/iss2/16/.

Uldall, Elizabeth. 1958. American 'molar' R and 'flapped' T. Revista do Laboratório de Fonética Experimental da Faculdade de Letras da Universidade de Coimbra 4.103-6.

Walker, Rachel, and Michael Proctor. 2013. Articulatory overlap in English syllables with postvocalic/x/. Proceedings of Meetings on Acoustics 19.060259. DOI: 10.1121/1 .4799574 .

Warner, Natasha; Amy Fountain; and Benjamin V. Tucker. 2009. Cues to perception of reduced flaps. Journal of the Acoustical Society of America 125.3317-27. DOI: 10.1121/1.3097773.

Weinreich, Uriel; William Labov; and Marvin Herzog. 1968. Empirical foundations for a theory of language change. Directions for historical linguistics, ed. by Winfred Lehmann and Yakov Malkiel, 95-105. Austin: University of Texas Press.

WeSTBURy, John R. 1994. X-ray microbeam speech production database user's handbook. Madison: University of Wisconsin.

Westbury, John R.; Michiko Hashi; and Mary J. Lindstrom. 1998. Differences among speakers in lingual articulation for American English / $\mathrm{x} /$. Speech Communication 26.203-26. DOI: 10.1016/S0167-6393(98)00058-2.

WodZinSKi, Sylvie M., and Stefan A. Frisch. 2006. Ultrasound study of velar-vowel coarticulation. Journal of the Acoustical Society of America 120.3373-74. DOI: 10.1121/1 .4781580 .

Yuan, Jiahong, and Mark Liberman. 2008. Speaker identification on the SCOTUS corpus. Proceedings of Acoustics '08, 5687-90.

ZaWAdSKi, Paul A., and D. P. KueHn. 1980. A cineradiographic study of static and dynamic aspects of American English /r/. Phonetica 37.253-66. DOI: 10.1159/000259995.

Zhou, Xinhui. 2009. An MRI-based articulatory and acoustic study of American English liquid sounds $/ r /$ and $/ l /$. College Park: University of Maryland dissertation.

Zhou, Xinhui; Carol Y. Espy-Wilson; Suzanne Boyce; Mark Tiede; Christy HolLAND; and ANN CHOе. 2008. A magnetic resonance imaging-based articulatory and acoustic study of 'retroflex' and 'bunched' American English /r/. Journal of the Acoustical Society of America 123.4466-81. DOI: 10.1121/1.2902168.

ZimmermanN, J. 1858. A grammatical sketch and vocabulary of the Akra- or Gã-language. Stuttgart: Gregg. 
Mielke

Department of English

North Carolina State University

Campus Box 8105

Raleigh, NC 27695-8105

[jimielke@ncsu.edu]

[todd.baker@und.edu] (Baker)

[dba@u.arizona.edu] (Archangeli)
[Received 19 March 2012;

revision invited 1 May 2013;

revision received 14 May 2014;

accepted 15 February 2015] 